\title{
Seismic performance assessment of non-code-conforming and code-conforming supporting structures of elevated tanks using conventional and risk-based decision models
}

\author{
Stefano Caprinozzi and Matjaž Dolšek \\ Faculty of Civil and Geodetic Engineering, University of Ljubljana, Slovenia
}

\begin{abstract}
s
The seismic performance of the supporting structure of the replica of an elevated tank that collapsed during the Kocaeli earthquake and its variant designed according to Eurocode 8 provisions was investigated. First, the performance of the tank was verified for the Kocaeli ground motion. Results of non-linear seismic response history analysis using simplified models accounting for different tank filling levels showed that the simplified model could provide qualitatively the same damage as were observed during the earthquake, while the seismic performance of the code-conforming tank was satisfactory. Then, the seismic performance assessment of the non-code- and code-conforming tanks was further investigated using the conventional decision model, which accounts for the demand-to-capacity ratio given the seismic design action, the conditional risk-based decision model and the risk-based decision model which utilise, respectively, the probability of exceeding a designated limit state for a given design seismic action and for a given period. The seismic performance of the non-code-conforming elevated tank was found insufficient by any of the three decision models, which indicated the need for action towards risk reduction for such structures. The opposite was realised for the code-conforming tank. However, the conventional decision model may be misleading because it indicated that the structure might be considered overdesigned, while risk-based decision model showed that the seismic performance of the code-conforming tank was close to the target value, set to $1 \%$ in 50 years. In the future, risk-targeted design approaches can improve decision-making in the design of critical components of industrial facilities.
\end{abstract}

Keywords: steel storage tanks, petrochemical plant, seismic fragility analysis, risk analysis, decision models, seismic action

\section{INTRODUCTION}

Industrial facilities are vital for the functionality of the built environment and community [1]. Due to increased environmental attention and fear of economic losses, the demand for procedures and tools that can be used to quantify and assess risks and estimate losses is higher than ever. Also, natural events such as earthquakes and hurricanes highlight the vulnerability of tanks, supporting structures, piping systems, and other units of industrial facilities, as discussed in [2-4]. However, excessive vulnerability is not only the consequence of a lack of knowledge in the estimation of demand and capacity. Vulnerability is also the consequence of the limited definition of performance objectives, which usually account only for the effect of a specific design earthquake rather than all possible earthquakes that can occur at the site of the critical unit during its lifetime. For instance, Vathi et al. [5] provided performance criteria for liquid storage tanks that involved only the concept of the demand-to-capacity ratio. However, in earthquake engineering, the performance objectives can be defined by considering risk-based performance metrics and the corresponding decision models. The US codes [6,7] consider a target probability of failure for a given period of time and a target probability of failure given a seismic intensity action, but the codes do not require that these performance criteria are verified explicitly. 
This paper was published in Engineering Structures. Please cite it as:

Caprinozzi S, Dolšek M. Seismic performance assessment of non-code-conforming and code-conforming supporting structures of elevated tanks using conventional and risk-based decision models. Engineering structures, 2021, 227, 111469, https://doi.org/10.1016/i.engstruct.2020.111469,

DOI: 10.1016/j.engstruct.2020.111469.

The informative Annex of the new Eurocode draft [8] provides a simplified, reliability-based verification format. However, risk assessment implies the fragility analysis of the examined structure, which is computationally demanding, as discussed by Salzano et al. [9] and Phan et al. [10]. Furthermore, the design for a target risk requires at least a few iterations of performance assessment using non-linear analysis and structural adjustment aimed at fulfilling the condition that the collapse risk is less than the target collapse risk [11].

The motivation for this study is to improve the understanding of seismic performance assessment of supporting structures of elevated tanks constructed in different periods and to investigate how different decision models can affect decision making about the seismic performance of elevated tanks. The first objective is to evaluate the seismic response of one new (i.e. code-conforming) and one existing, reinforced-concrete supporting structure of elevated steel storage tanks subjected to the Kocaeli ground motion. The existing tank was damaged during the Kocaeli earthquake, as reported in the aftershock survey by Sezen et al. [12]. Because the existing tank does not fulfil the requirements of Eurocode 8, it is termed as the non-code-conforming tank. The code-conforming supporting structure of the tank was designed following Eurocode 8 [13] provisions for the ductility class high (DCH) structures.

The second objective of the study is to evaluate the seismic performance of the investigated tanks by the conventional decision model, which involves the demand-to-capacity ratio given the seismic design action, and two types of metrics considering the probability of exceeding a designated limit state. The conditional risk-based metric takes into account the target (acceptable) probability of exceeding a designated limit state (LS) given the design earthquake. In contrast, the risk-based metric is more general because it accounts for the target (acceptable) probability of exceeding a designated limit state for a specified period. In the latest case, the decision model considered the effects of all ground motions that can occur during the observed period.

First, the investigated tanks, numerical models and limit states are described. Then the seismic performance of the tank-supporting structure is investigated for the Kocaeli ground motion. Metrics and the corresponding decision models for the seismic performance evaluation of structures using non-linear response history analysis are described. In the second part of the paper, the seismic performance assessment of non-code- and code-conforming tanks was further investigated using the conventional, the conditional risk-based decision model and the risk-based decision model. Finally, the results of the performance assessments are presented and discussed.

\section{DESCRIPTION OF INVESTIGATED ELEVATED TANKS, NUMERICAL MODELS AND LIMIT STATES}

The existing (i.e. non-code-conforming) and the code-conforming tanks and their supporting structures are introduced. The first example is an elevated steel storage tank located in Turkey. It was constructed in the 90s following the construction procedure of that period. Such a tank with a high filling level collapsed in 1999 due to the Kocaeli earthquake, while tanks with lower filling level did not collapse. A decade later, Eurocode standards were released. The supporting structure of the non-code-conforming elevated steel storage tank did not fulfil the requirements of the newest code. For comparison, a codeconforming support structure was designed according to Eurocode 8 provisions for a code-conforming tank with the same height and diameter as the non-code-conforming tank. It is assumed that both tanks are at the location of the existing tank. 
This paper was published in Engineering Structures. Please cite it as:

Caprinozzi S, Dolšek M. Seismic performance assessment of non-code-conforming and code-conforming supporting structures of elevated tanks using conventional and risk-based decision models. Engineering structures, 2021, 227, 111469, https://doi.org/10.1016/j.engstruct.2020.111469,

DOI: $10.1016 /$ j.engstruct.2020.111469.

\subsection{Non-code-conforming tank}

The non-code-conforming elevated steel storage tank is presented in Fig. 1. The tank was located in Izmit, Kocaeli county, which is a high seismicity region in Turkey. It collapsed on August 17, 1999, when an $\mathrm{M}_{\mathrm{w}}=7.4$ earthquake struck the Kocaeli region. The earthquake affected millions of people and caused more than 15 billion USD in damage [14]. The area affected by the event is one of the most industrialised regions in Turkey. A total of $48 \%$ of all heavily damaged structures caused by the earthquake were observed in this region [15], which also includes the collapse of the supporting reinforced concrete structure of the investigated tank (Fig. 1).

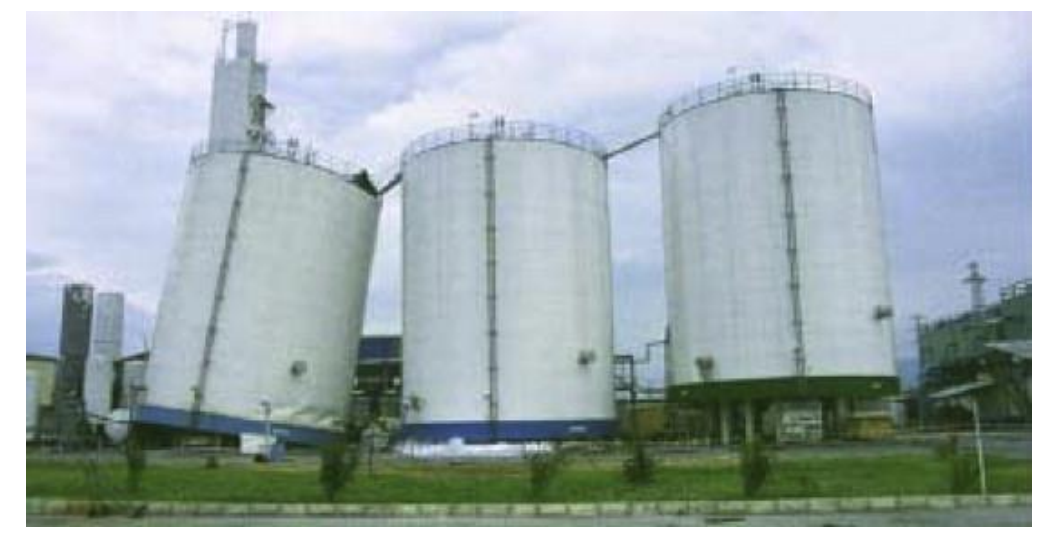

Fig. 1. View of the non-code-conforming elevated steel storage tank that collapsed during the earthquake [12].

The non-code-conforming tank was practically new when the earthquake hit. The tank was built in 1995 and consisted of two concentric stainless-steel walls, the outer with an outside diameter of $14.6 \mathrm{~m}$ and the inner with an outside diameter of $12.8 \mathrm{~m}$. The gap between the walls was filled with insulation. The tank was supported on a reinforced concrete slab with a diameter of $14.6 \mathrm{~m}$ and a thickness of $1.07 \mathrm{~m}$. The slab was supported by sixteen reinforced concrete columns with a diameter of $500 \mathrm{~mm}$. The height of the columns was $2.5 \mathrm{~m}$. Each column was reinforced with sixteen, $16 \mathrm{~mm}$ diameter longitudinal bars and $8 \mathrm{~mm}$ diameter stirrups at $100 \mathrm{~mm}$ with yielding stress of $420 \mathrm{MPa}$ [16]. The overall height of the tank was about $16 \mathrm{~m}$.

\subsection{Code-conforming tank}

The supporting structure of the code-conforming elevated tank was improved. Columns were designed according to Eurocode 8 for the ductility class high $(\mathrm{DCH})$. The new code required increasing the column diameter from $50 \mathrm{~cm}$ to $70 \mathrm{~cm}$. Concrete C30/37 and steel S500C were used for the columns. The resulting cross-section of the columns and the corresponding longitudinal and transverse reinforcement are presented in Fig. 2. 
This paper was published in Engineering Structures. Please cite it as:

Caprinozzi S, Dolšek M. Seismic performance assessment of non-code-conforming and code-conforming supporting structures of elevated tanks using conventional and risk-based decision models. Engineering structures, 2021, 227, 111469, https://doi.org/10.1016/j.engstruct.2020.111469,

DOI: 10.1016/j.engstruct.2020.111469.

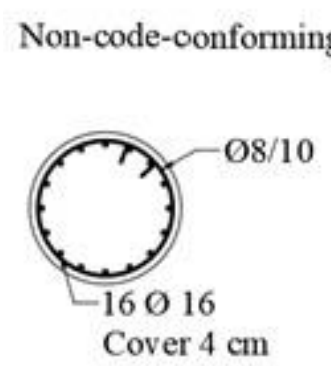

(a)
Code-oonforming

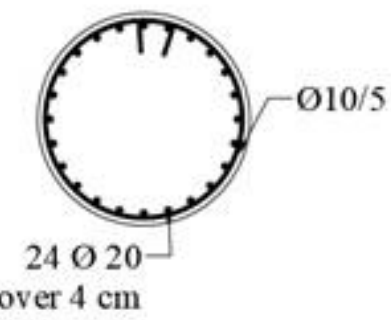

(b)

Fig. 2. Cross-section of the columns of supporting structure of (a) non-code-conforming elevated tank and (b) code-conforming elevated tank.

Note that in the design, loads were combined with the basic load combinations (actions for permanent or transient design situations) according to EN 1990:2002 6.4.3.2. The effects of the contents shall be considered in the variable loads for two tank filling levels: empty or full, as prescribed in Eurocode [17]. The seismic design action was defined according to Eurocode [13] by considering return period $T_{N C R}=$ 475 years because the investigated tank is classified as a structure of ordinary importance. The design peak ground acceleration (PGA) was then obtained from the Kocaeli seismic hazard function (Fig. 3) using the results of the SHARE project by Woessnert et al. [18]. The resulting PGA for the return period of 475 years is $0.5 \mathrm{~g}$.

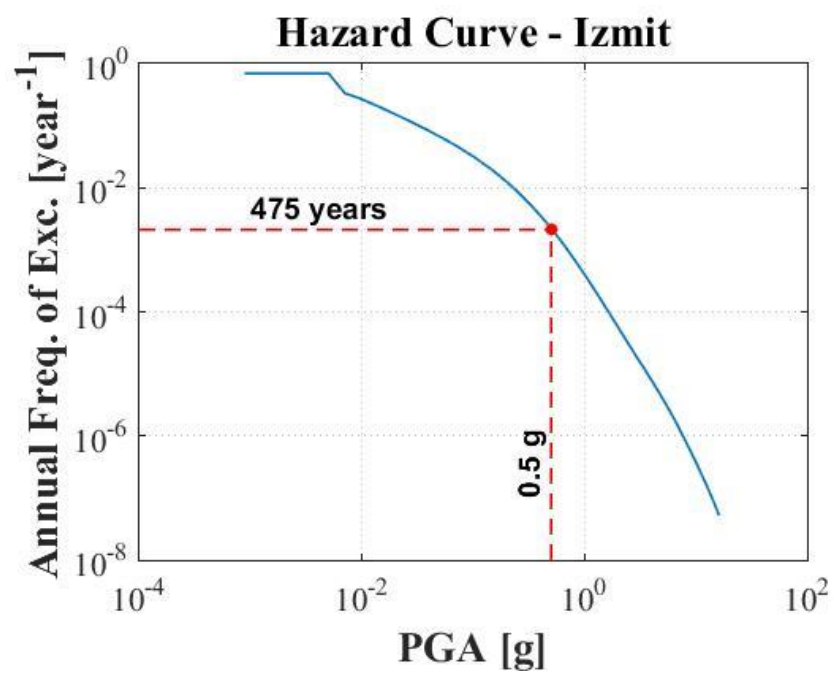

Fig. 3. Seismic hazard function for Kocaeli based on the SHARE project.

A soil type A was assumed. The importance factor $\gamma_{I}$ was considered unitary because it was related to a 'medium risk to life and local economic or social consequences of failure belong to Class II' as prescribed by the code [17]. The supporting structure was classified as the 'Moment resisting frames'. Hence, the initial value of the behaviour factor was assumed to be 4.95 for $\mathrm{DCH}$. This value of the behaviour factor was, according to the provisions of Eurocode 8-4, multiplied by 0.7 [17], which resulted in a final behaviour factor of 3.47. The seismic demand was estimated based on the seismic combination considering the recommended value of $\varphi=1$ for a full tank and $\varphi=0$ for an empty tank. Because the importance factor $\gamma_{I}=1$, the design peak ground acceleration $a_{g, R}=0.5 \mathrm{~g}$, which corresponds to the 
This paper was published in Engineering Structures. Please cite it as:

Caprinozzi S, Dolšek M. Seismic performance assessment of non-code-conforming and code-conforming supporting structures of elevated tanks using conventional and risk-based decision models. Engineering structures, 2021, 227, 111469, https://doi.org/10.1016/j.engstruct.2020.111469,

DOI: 10.1016/j.engstruct.2020.111469.

return period of 475 years. Note that the content of the tank was liquid with a density of $1150 \mathrm{~kg} / \mathrm{m}^{3}$ and, for the present study, the height of the content was assumed to vary from $90 \%$ to $0 \%$ of the tank height. During the Kocaeli earthquake, two tanks were filled to $85 \%$ and the remaining tank was filled to $25 \%$.

The presented structural models emphasise the model of the columns of the supporting structure, which are the most vulnerable components of the tanks. The steel tank is thus modelled by a 3D finite element stick model (Fig. 4). This latter is a simplified but computationally efficient numerical model. It comprises lumped masses, as presented in Fig. 4, which are connected to the supporting structure by cantilevers that have similar dynamic characteristics and can be observed in the tanks due to the impulsive and convective response. The tank mass is rigidly connected. Supporting columns and cantilevers used to connect lumped impulsive and convective masses to the support structure are modelled employing beam elements. The columns' heads and the centre of the reinforced concrete slab are connected rigidly (Fig. 4). Three nodes circled in yellow in Fig. 4 are rigidly connected to simulate the thickness of the slab. The slab mass is considered in the central node.

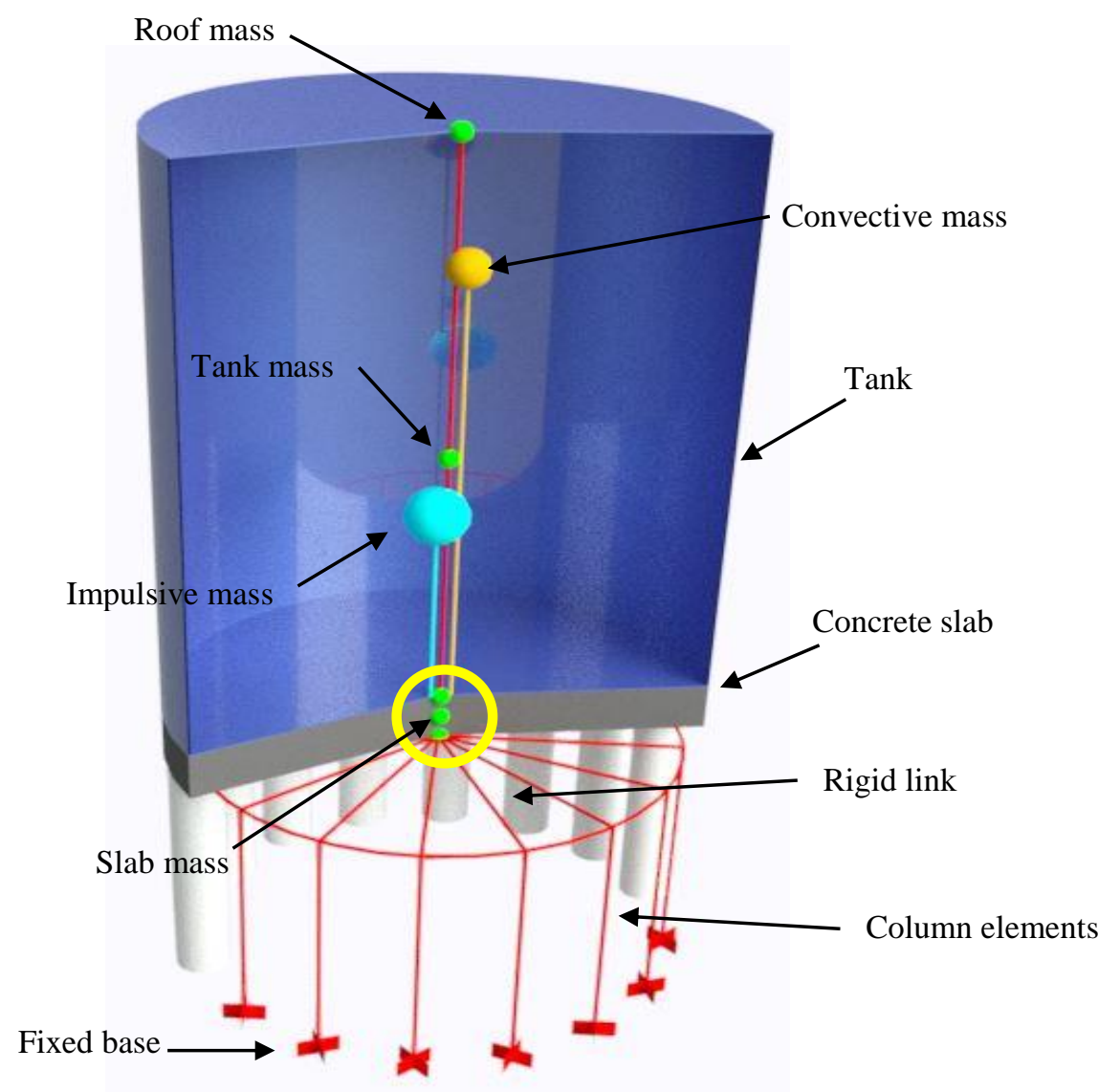

Fig. 4. The 3D model of the elevated tank comprising column elements and the rigid links to simulate the support structure, the independent cantilevers used to connect impulsive and convective masses, and the tank and roof masses rigidly connected to the slab nodes with the slab mass at the middle. 
This paper was published in Engineering Structures. Please cite it as:

Caprinozzi S, Dolšek M. Seismic performance assessment of non-code-conforming and code-conforming supporting structures of elevated tanks using conventional and risk-based decision models. Engineering structures, 2021, 227, 111469, https://doi.org/10.1016/j.engstruct.2020.111469,

DOI: 10.1016/j.engstruct.2020.111469.

The model is consistent with the Eurocode 8-4 provisions [17]. Note that the code provides a simplified approach for the modelling of the tank-liquid system concerning fixed-base, cylindrical tanks. However, these provisions can be used even for modelling the elevated tanks because they are fixed to the rigid slab of the supporting structure.

The insulating material between the external and internal walls was neglected because its mass and stiffness have a minor effect on the seismic response of the supporting structure. The mass of the tank and the roof were rigidly connected to the slab, while the lumped masses of the content were connected to the slab by linear elastic cantilevers with appropriate constants. Lumped masses representing the content were decomposed to the impulsive mass, $m_{i}$, and the convective mass, $m_{c}$, which were connected by linear elastic cantilevers with stiffness equal to $k_{i}$ and $k_{c}$, respectively. Impulsive and convective masses were calculated according to the tabled values provided in Eurocode [17]. Table 1 presents a resume of masses, elevation, and stiffness of the connection, from $90 \%$ filling level to $20 \%$ filling level. Tank and roof masses were $38 \mathrm{t}$ and $6 \mathrm{t}$ respectively, while the support structure mass was $364 \mathrm{t}$.

In addition to the mass and the stiffness of the cantilevers, which are used to simulate the convective and impulsive response of the tank, it is necessary to define the model for the viscous damping. In this respect, according to the provisions of Eurocode $([13,17])$, a damping ratio of $5 \%$ was accounted for all modes through the design acceleration spectrum.

Table 1. Impulsive and convective masses and stiffness for $90 \%, 85 \%, 25 \%$, and $20 \%$ filling levels of the tank. The elevations of the masses are also presented.

\begin{tabular}{ccccc}
\hline Mass type & Filling level & Mass [t] & Elevation [m] & Stiffness [KN/m] \\
\hline & $90 \%$ & $1.7 \cdot 10^{3}$ & 6.14 & $1.3 \cdot 10^{6}$ \\
\multirow{2}{*}{$m_{i}$} & $85 \%$ & $1.6 \cdot 10^{3}$ & 5.77 & $1.4 \cdot 10^{6}$ \\
& $25 \%$ & $2.2 \cdot 10^{2}$ & 1.6 & $1.7 \cdot 10^{6}$ \\
& $20 \%$ & $1.4 \cdot 10^{2}$ & 1.28 & $1.5 \cdot 10^{6}$ \\
\hline \multirow{2}{*}{$m_{c}$} & $90 \%$ & $4.5 \cdot 10^{2}$ & 11 & $1.3 \cdot 10^{3}$ \\
& $85 \%$ & $4.5 \cdot 10^{2}$ & 10.3 & $1.3 \cdot 10^{3}$ \\
& $25 \%$ & $3.7 \cdot 10^{2}$ & 2.2 & $8.6 \cdot 10^{2}$ \\
\hline
\end{tabular}

A linear elastic model was developed according to the Eurocode provisions for the design of the supporting structure. The modelling philosophy was the same as that previously introduced, while mechanical properties and material adopted are listed in Table 2. The model (Fig. 5) was developed in SAP2000 [19] by analogy to the information presented in Fig. 4. The seismic demand on columns was obtained by the response spectrum analysis. Once the design had been created, the seismic performance assessment of the code-conforming tanks was carried out using a non-linear model, which was developed in OpenSees [20] as described in Section 2.3. 
This paper was published in Engineering Structures. Please cite it as:

Caprinozzi S, Dolšek M. Seismic performance assessment of non-code-conforming and code-conforming supporting structures of elevated tanks using conventional and risk-based decision models. Engineering structures, 2021, 227, 111469, https://doi.org/10.1016/j.engstruct.2020.111469,

DOI: 10.1016/j.engstruct.2020.111469.

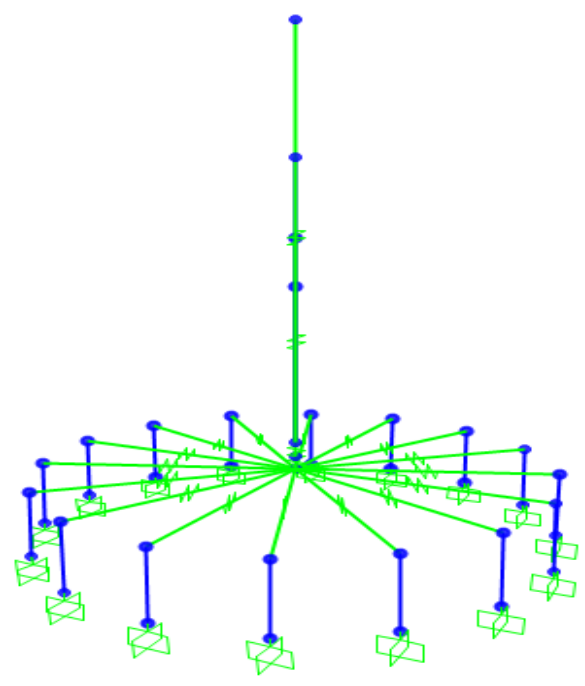

Fig. 5. Linear elastic model of the elevated tank developed in SAP2000.

\subsection{Non-linear model for the seismic performance assessment of the elevated tanks}

The non-linear model of the elevated tank was developed in OpenSees. The supporting reinforced concrete columns were modelled with 3D non-linear beam-column elements with fibre cross-sections. The column section was divided into two parts to consider the confinement effect of the stirrups on the concrete core, as presented in Fig. 6. The confinement effect was taken into account by increasing the compressive concrete strength as allowed by Eurocode [21]. Concrete behaviour was modelled using the Kent-Scott-Park model [22], which is already implemented in OpenSees throughout uniaxial material Concrete01. The stress-strain behaviour of reinforcing rebars was simulated using the GiuffréMenegotto-Pinto model coded in the OpenSees environment and named Steel02 [23]. The adopted mechanical properties of the material used in the model are presented in Table 2. Column heads were, later, rigidly connected to the centre of gravity of the supporting slab. Each lumped mass simulating the fluid and tank itself was connected to the supporting slab by an elastic element with appropriate stiffness as previously discussed. The damping ratio, assumed to be proportional to the convective mass and impulsive mass, was assumed to be $0.5 \%$ and $2 \%$, respectively [24].

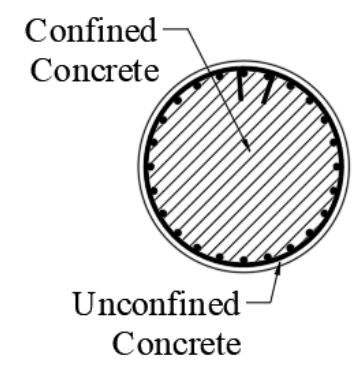

Fig. 6. Confined and unconfined column cross-section.

The columns of the non-code-conforming tanks were particularly vulnerable to shear failures, as demonstrated by the failure mechanism during the Kocaeli seismic event [12]. The shear force - shear deformation behaviour for the pure-shear failure of the supporting structure was simulated employing 
This paper was published in Engineering Structures. Please cite it as:

Caprinozzi S, Dolšek M. Seismic performance assessment of non-code-conforming and code-conforming supporting structures of elevated tanks using conventional and risk-based decision models. Engineering structures, 2021, 227, 111469, https://doi.org/10.1016/j.engstruct.2020.111469,

DOI: 10.1016/j.engstruct.2020.111469.

the model introduced by Setzler et al. [25], which is not implemented in the OpenSees software. To introduce the stress-strain model to the supporting reinforced concrete columns, the section aggregator command of the OpenSees was used to provide a uniaxial hysteretic material to represent the sectional shear behaviour (Fig. 7), as suggested by Phan et al. [16].

However, the first and the second characteristic points of the shear force - shear deformation relationship of the so-defined material were calculated based on the modified compression field theory using the Response 2000 software [26]. The first and second point characterise, respectively, the shear deformation at which the first crack appears, $\gamma_{\mathrm{cr}}$, and the shear deformation corresponding to the maximum shear force, $\gamma_{\mathrm{y}}$. The third point, $\gamma_{\mathrm{u}}$, was obtained according to the procedure proposed by Elwood et al. [27]. The shear force of the third point corresponds to the $80 \%$ drop of maximum shear force. The values of the described characteristic points of shear force - shear deformation relationship are presented in Table 3 and Table 4 for each considered filling level for the non-code- and codeconforming tanks, respectively.

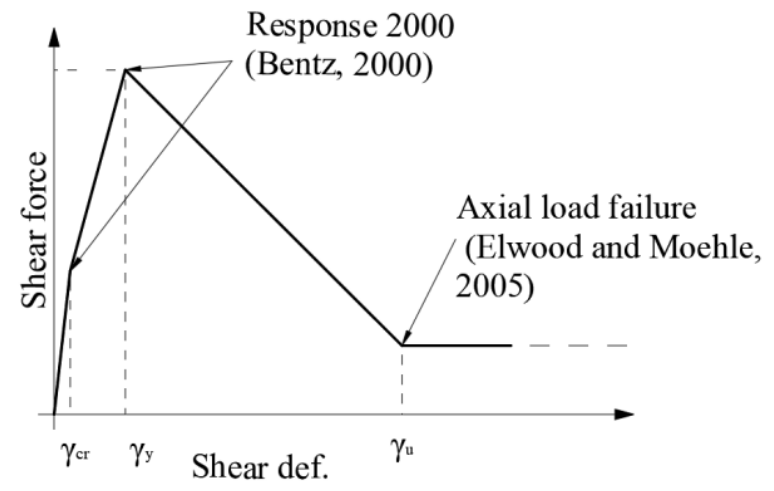

Fig. 7. The shear force - shear deformation relationship of the columns.

Table 2. Material properties adopted for the non-linear model.

\begin{tabular}{ccccc}
\hline Material & $\begin{array}{c}\text { Density } \\
{\left[\mathbf{k g}^{\mathbf{3}} \mathbf{m}^{3}\right]}\end{array}$ & $\mathbf{E}[\mathbf{M P a}]$ & \multicolumn{2}{c}{ Strength [MPa] } \\
& & Non-code-conforming & Code-conforming \\
\hline Confined concrete & 2500 & 32000 & 39 & 49 \\
Unconfined concrete & 2500 & 32000 & 30 & 38 \\
Reinforcement & 7850 & 210000 & 420 & 575 \\
\hline
\end{tabular}

Table 3. The characteristic points of shear force - shear deformation relationship in the non-linear model of the columns of the non-code-conforming supporting structure of the elevated tank.

\begin{tabular}{ccccccc}
\hline \multirow{2}{*}{ Filling level } & \multicolumn{5}{c}{ Non-code-conforming } \\
& $\boldsymbol{\gamma}_{\mathrm{cr}}[\boldsymbol{\%}]$ & Shear $[\mathbf{K N}]$ & $\gamma_{\mathbf{y}}[\boldsymbol{\%}]$ & Shear $[\mathbf{K N}]$ & $\gamma_{\mathbf{u}}[\%]$ & Shear $[\mathbf{K N}]$ \\
\hline $90 \%$ & 0.01 & 103 & 0.03 & 583 & 10 & 117 \\
$80 \%$ & 0.01 & 103 & 0.07 & 496 & 10.33 & 99 \\
$70 \%$ & 0.01 & 103 & 0.08 & 491 & 10.35 & 98 \\
$60 \%$ & 0.01 & 103 & 0.08 & 481 & 10.32 & 96 \\
$50 \%$ & 0.01 & 103 & 0.08 & 470 & 10.37 & 94 \\
\hline
\end{tabular}


This paper was published in Engineering Structures. Please cite it as:

Caprinozzi S, Dolšek M. Seismic performance assessment of non-code-conforming and code-conforming supporting structures of elevated tanks using conventional and risk-based decision models. Engineering structures, 2021, 227, 111469, https://doi.org/10.1016/j.engstruct.2020.111469,

DOI: 10.1016/j.engstruct.2020.111469.

\begin{tabular}{ccccccc}
\hline $40 \%$ & 0.01 & 103 & 0.02 & 448 & 10.38 & 90 \\
$30 \%$ & 0.01 & 103 & 0.02 & 413 & 10.39 & 83 \\
$20 \%$ & 0.01 & 103 & 0.02 & 414 & 10.40 & 83 \\
$0 \%$ & 0.01 & 104 & 1.33 & 397 & 10.40 & 79 \\
\hline
\end{tabular}

Table 4. The characteristic points of shear force - shear deformation relationship in the non-linear model of the columns of the code-conforming supporting structure of the elevated tank.

\begin{tabular}{ccccccc}
\hline \multirow{2}{*}{ Filling level } & \multicolumn{5}{c}{ Code-conforming } \\
& $\boldsymbol{\gamma}_{\text {cr }}[\boldsymbol{\%}]$ & Shear $[\mathbf{K N}]$ & $\boldsymbol{\gamma}_{\mathbf{y}}[\boldsymbol{\%}]$ & Shear $[\mathbf{K N}]$ & $\boldsymbol{\gamma}_{\mathbf{u}}[\%]$ & Shear $[\mathbf{K N}]$ \\
\hline $90 \%$ & 0.46 & 902 & 1.09 & 1295 & 10.43 & 259 \\
$80 \%$ & 0.46 & 934 & 1.10 & 1328 & 10.43 & 266 \\
$70 \%$ & 0.47 & 962 & 1.11 & 1341 & 10.43 & 268 \\
$60 \%$ & 0.47 & 988 & 1.12 & 1353 & 10.44 & 271 \\
$50 \%$ & 0.43 & 957 & 1.13 & 1355 & 10.44 & 271 \\
$40 \%$ & 0.47 & 1041 & 1.14 & 1360 & 10.44 & 272 \\
$30 \%$ & 0.43 & 1018 & 1.16 & 1363 & 10.44 & 273 \\
$20 \%$ & 0.40 & 990 & 1.02 & 1378 & 10.44 & 276 \\
$0 \%$ & 0.01 & 338 & 1.05 & 1389 & 10.41 & 278 \\
\hline
\end{tabular}

\subsection{Definition of limit state}

Several failures modes can occur in the industrial facilities which have been an object of interest by several authors [28-30]. Moreover, the strengthening of the supporting structure may cause other failure modes mostly related to the tank itself (e.g. tank wall failures due to buckling, the anchorage system failure, or the connected fittings failures). However, in the present study, attention was paid only to the support structure.

The near-collapse (NC) limit state was defined by the damage observed in the columns of the supporting structure. Note that other failure modes related to the tank itself (e.g. tank wall failures due to buckling), the anchorage system, or the connected fittings (e.g. nozzles, pipes, etc.) may occur. The present study assumed that the tank and other components of the system were less vulnerable than the supporting structure. In a more general case, the performance of all components of the system should be considered.

The NC limit state was assumed to occur when the chord rotation exceeds the ultimate chord rotation, which was assumed to correspond to $85 \%$ strength in the post-capping range in the case of the codeconforming tank. Such an approach is not fully consistent with the Eurocode [31] definition, which prescribes an NC limit state at $80 \%$ strength. Nevertheless, the authors decided to adopt a slightly more stringent criterion than that defined in the Eurocode. In the case of the non-code-conforming tank, the $\mathrm{NC}$ chord rotation was assumed to correspond to the maximum shear force in the pushover analyses because of the brittle behaviour displayed in the Kocaeli earthquake [12].

Such an approach guaranteed consistency between the definition of the NC limit state and the non-linear model. For simplicity, it was decided to estimate the NC chord rotation by performing pushover analysis, as demonstrated in Fig. 8.

Pushover analyses were performed and accounted for the most relevant modal shape capable of exciting most of the total mass (support structure and content), providing, in this respect, a modal-shaped loading profile. In this manner, even the variation of the filling level, thus the content mass, was considered. 
This paper was published in Engineering Structures. Please cite it as:

Caprinozzi S, Dolšek M. Seismic performance assessment of non-code-conforming and code-conforming supporting structures of elevated tanks using conventional and risk-based decision models. Engineering structures, 2021, 227, 111469, https://doi.org/10.1016/j.engstruct.2020.111469,

DOI: 10.1016/j.engstruct.2020.111469.

Note that in Fig. 8, the pushover curves and LS for the code-conforming and the non-code-conforming tanks are presented for filling levels from $90 \%$ to $0 \%$. Note that, due to the circular shape of the columns and supporting structure, the pushover curves are not affected by the loading direction.

Based on the pushover analysis, the NC chord rotations were estimated for each filling level of the tank. They were used to identify the NC limit state in the response history analysis. The resulting values of the NC chord rotations are presented in Table 5.

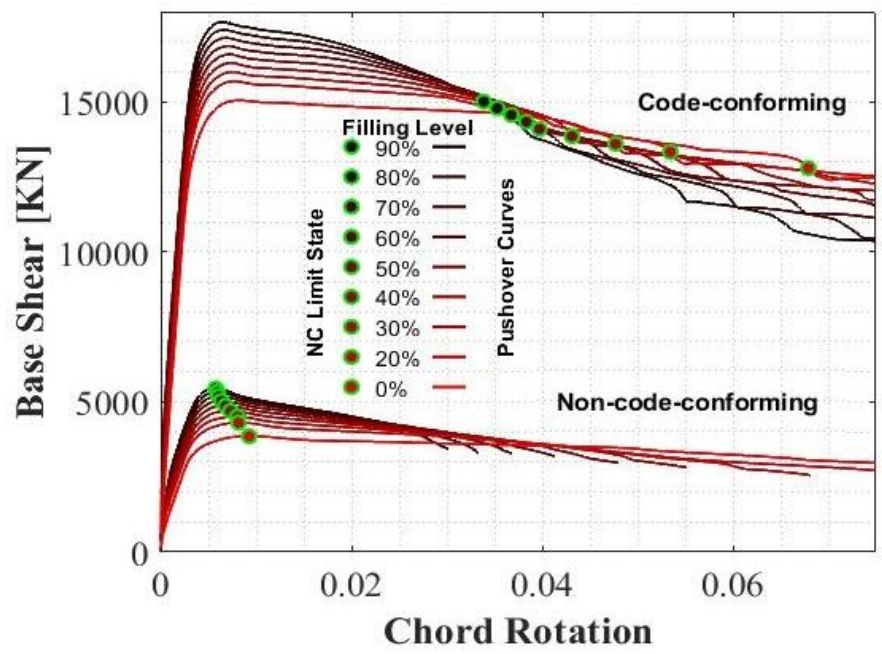

Fig. 8. The shear force - chord rotation relationship of the columns.

Table 5. The chord rotation capacities for the NC limit state at the different tank filling levels.

\begin{tabular}{ccc}
\hline Filling level & \multicolumn{2}{c}{ NC chord rotation } \\
& Non-code-conforming & Code-conforming \\
\hline $90 \%$ & 0.006 & 0.034 \\
$80 \%$ & 0.006 & 0.035 \\
$70 \%$ & 0.006 & 0.037 \\
$60 \%$ & 0.006 & 0.038 \\
$50 \%$ & 0.007 & 0.040 \\
$40 \%$ & 0.007 & 0.043 \\
$30 \%$ & 0.008 & 0.048 \\
$20 \%$ & 0.008 & 0.053 \\
$0 \%$ & 0.009 & 0.068 \\
\hline
\end{tabular}

\section{SEISMIC PERFORMANCE ASSESSMENT OF TANKS SUBJECTED TO KOCAELI GROUND MOTION}

During the Kocaeli earthquake, the peak ground accelerations were recorded in the range from $0.2 \mathrm{~g}$ to $0.4 \mathrm{~g}$ [12]. The ground motion considered in this study was recorded at the Kocaeli recording station, which is located in the same county as the elevated tanks that collapsed during the earthquake. The peak ground accelerations for two horizontal components were respectively PGA $=0.15 \mathrm{~g}$ and $\mathrm{PGA}=0.22 \mathrm{~g}$, 
This paper was published in Engineering Structures. Please cite it as:

Caprinozzi S, Dolšek M. Seismic performance assessment of non-code-conforming and code-conforming supporting structures of elevated tanks using conventional and risk-based decision models. Engineering structures, 2021, 227, 111469, https://doi.org/10.1016/j.engstruct.2020.111469,

DOI: 10.1016/j.engstruct.2020.111469.

for Direction 1 and Direction 2, respectively. The vertical component was neglected in the response history analysis [13]. The ground motions and the corresponding acceleration spectra are presented in Fig. 9.
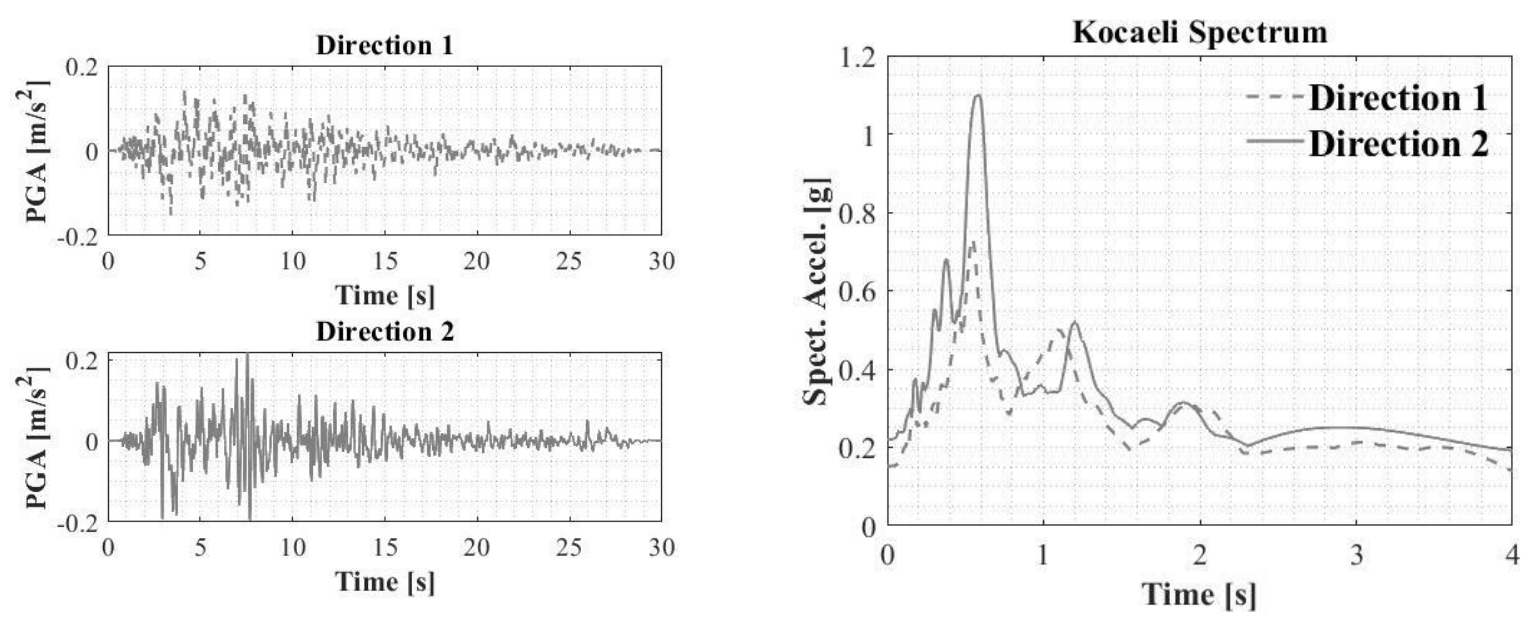

Fig. 9. Horizontal components of the Kocaeli ground motion and the corresponding spectral accelerations.

The seismic response of the non-code-conforming tank is first simulated for the Kocaeli ground motion to compare the simulated damage of the tank with the damage observed after the earthquake and to observe the impact of the tank filling level on the seismic response of the tank. In addition, the seismic response of the code-conforming tanks to the Kocaeli ground motion is also presented. The damage associated with the NC limit state is observed with the demand-to-capacity ratio, which considers the NC chord rotation presented in Table 5. The chord rotation demand was calculated as the ratio between the maximal displacement at the top of the columns and the height of the columns.

The resulting demand-to-capacity ratios are presented in Fig. 10 (a) and Fig. 10 (b) for the non-codeconforming and the code-conforming tank, respectively. The results are presented for $85 \%$ and $25 \%$ filling levels, which were the levels in the tanks during the Kocaeli earthquake. The NC limit state was exceeded in the non-code-conforming tank filled at $85 \%$, while no exceedances were observed for the tanks filled to $25 \%$ of the filling level. The observed performance of the non-code-conforming tank is similar to the performance of the actual tanks during the Kocaeli earthquake. The tanks with $85 \%$ tank filling level collapsed, while the tank with $25 \%$ was undamaged.

Some elevated tanks collapsed during the Kocaeli earthquake. If the supporting structure had been designed according to Eurocode, the damage to the supporting structure would have been negligible, which was proven by simulating the seismic response of the code-conforming tanks. Fig. 10 (b) shows that the demand-to-capacity ratio in the columns of the supporting structure is on the order of 0.1 if the filling level of the tank was $85 \%$. The seismic performance of the tank's supporting structure designed for DCH was observed to be almost elastic. 
This paper was published in Engineering Structures. Please cite it as:

Caprinozzi S, Dolšek M. Seismic performance assessment of non-code-conforming and code-conforming supporting structures of elevated tanks using conventional and risk-based decision models. Engineering structures, 2021, 227, 111469, https://doi.org/10.1016/j.engstruct.2020.111469,

DOI: 10.1016/j.engstruct.2020.111469.
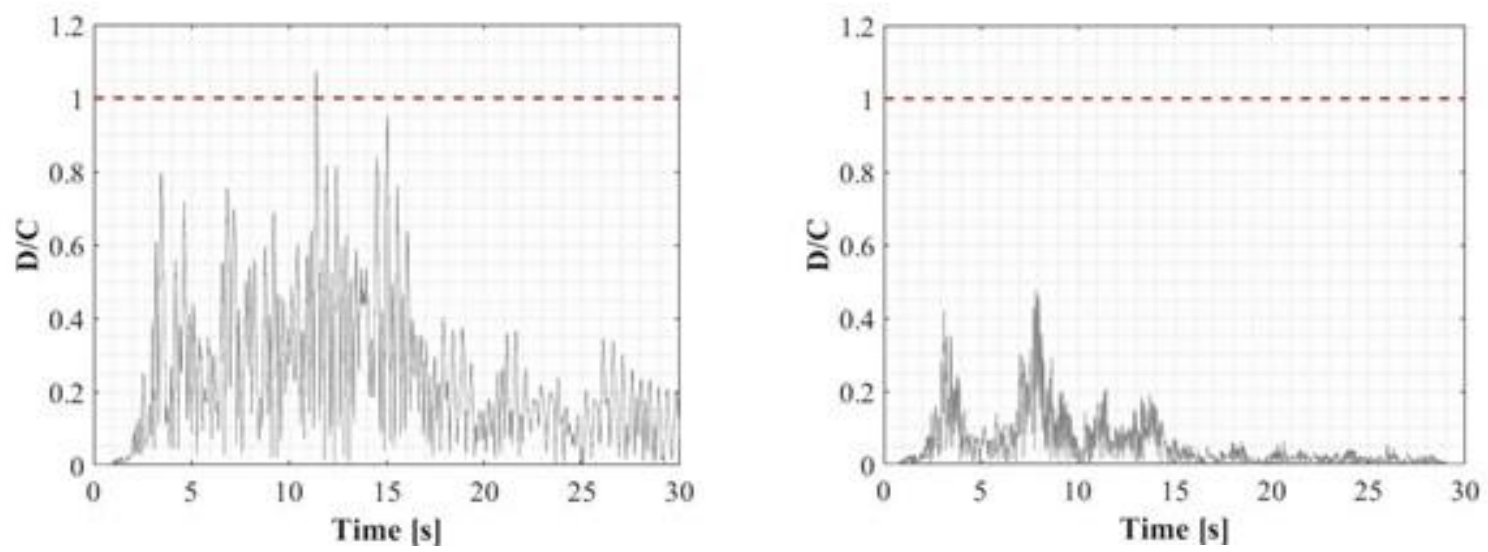

(a)
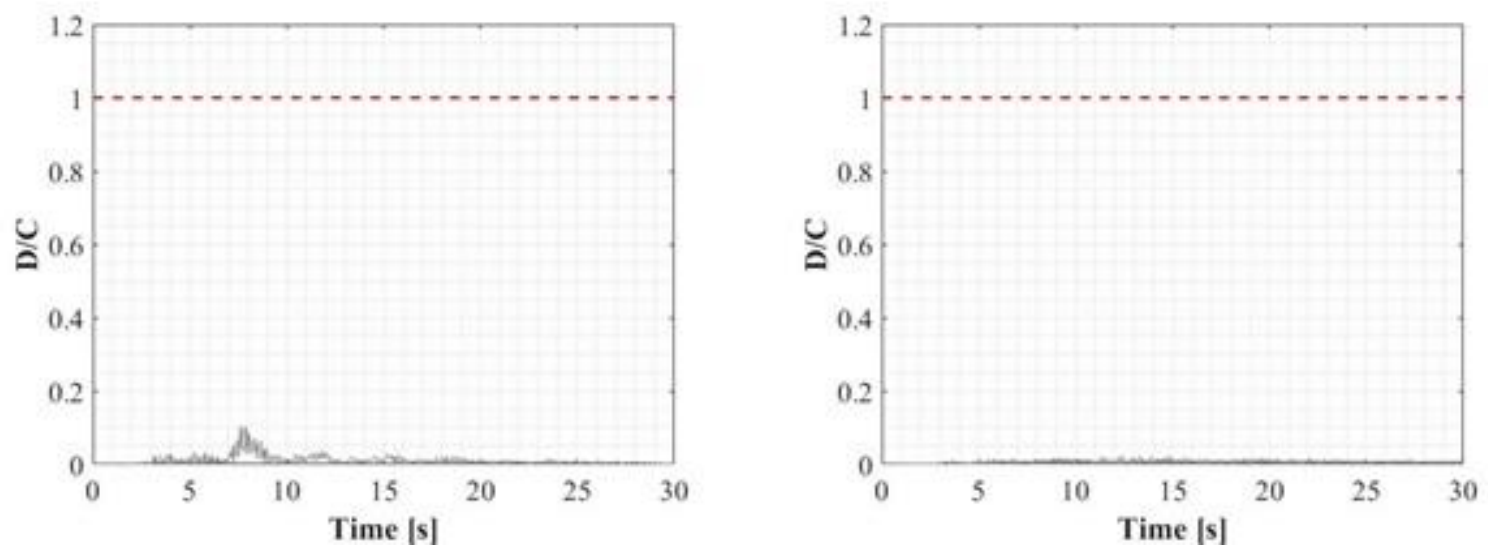

(b)

Fig. 10. The simulated demand-to-capacity ratio in the columns in the case of the Kocaeli earthquake for (a) the non-code-conforming tank and (b) the code-conforming tank, with the tanks filled to $85 \%$ (left) or 25\% (right).

Furthermore, the increase in the filling level causes a greater mass and longer impulsive vibration period (Table 6), while the convective vibration period decreases by increasing the filling level (Table 6). For this ground motion, the increase of the impulsive period almost always resulted in higher spectral acceleration (see Fig. 11), which consequently increased seismic forces. On the other hand, the variation of the filling has a small impact on the seismic action due to convective mass because the seismic action effects of convective mass are usually marginal even for the most non-slender tanks [32]. Namely, the convective mass is smaller in comparison to the impulsive mass, and spectral accelerations related to high vibration period of the convective response (i.e. from 3.7 to $4.4 \mathrm{~s}$ in the case of the investigated tanks) are very small. Note that periods presented in Table 6 were calculated according to the Eurocode 8-4 [17]. However, the maximum allowable chord rotation in the support structure (see Table 5) reduces with the increase of the filling level (Table 5). Thus, exceeding the capacity of the columns is most likely for configurations with a high level of filling. Due to non-linear effects, exceptions are possible.

Table 6. Impulsive $\left(T_{i}\right)$ and convective $\left(T_{c}\right)$ periods for filling levels ranging from $90 \%$ to $20 \%$.

\begin{tabular}{lcccccccc}
\hline Filling level & $\mathbf{9 0 \%}$ & $\mathbf{8 0 \%}$ & $\mathbf{7 0 \%}$ & $\mathbf{6 0 \%}$ & $\mathbf{5 0 \%}$ & $\mathbf{4 0 \%}$ & $\mathbf{3 0 \%}$ & $\mathbf{2 0 \%}$ \\
\hline $\boldsymbol{T}_{\boldsymbol{i}}[\mathrm{s}]$ & 0.22 & 0.19 & 0.17 & 0.14 & 0.12 & 0.09 & 0.08 & 0.06 \\
$\boldsymbol{T}_{c}[\mathrm{~s}]$ & 3.74 & 3.74 & 3.74 & 3.74 & 3.80 & 3.85 & 4.01 & 4.40 \\
\hline
\end{tabular}


This paper was published in Engineering Structures. Please cite it as:

Caprinozzi S, Dolšek M. Seismic performance assessment of non-code-conforming and code-conforming supporting structures of elevated tanks using conventional and risk-based decision models. Engineering structures, 2021, 227, 111469, https://doi.org/10.1016/j.engstruct.2020.111469,

DOI: 10.1016/j.engstruct.2020.111469.

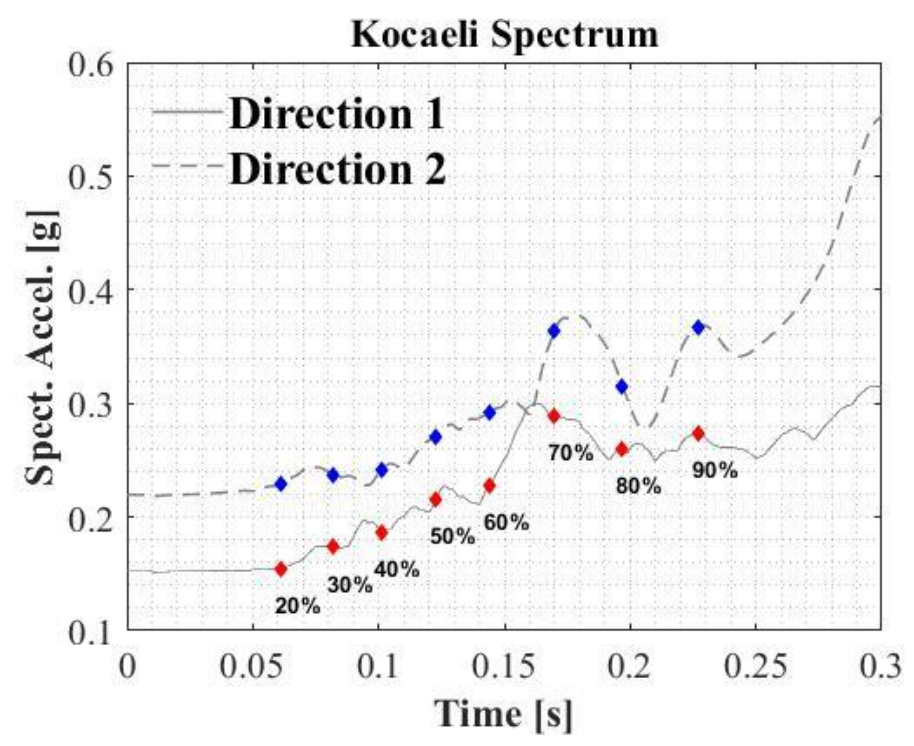

Fig. 11. Corresponding spectral acceleration for the impulsive periods according to different filling levels for the Kocaeli spectrum in both horizontal directions.

\section{SEISMIC PERFORMANCE ASSESSMENT OF TANKS USING THREE DECISION MODELS}

\subsection{Description of conventional, conditional risk-based and risk-based decision models}

Three decision models are presented and described. Fig. 12 presents the workflow and the decisionmaking process for all the three decision models to highlight similitudes and differences (red dashed border) that distinguish each decision model from the others. The two risk-based decision models share the need for a proper seismic hazard site characterisation to establish the seismic intensity for the definition of the most appropriate target spectrum. The definition of the target spectrum is the first process common for all three decision models, but the resulting target spectra differ.

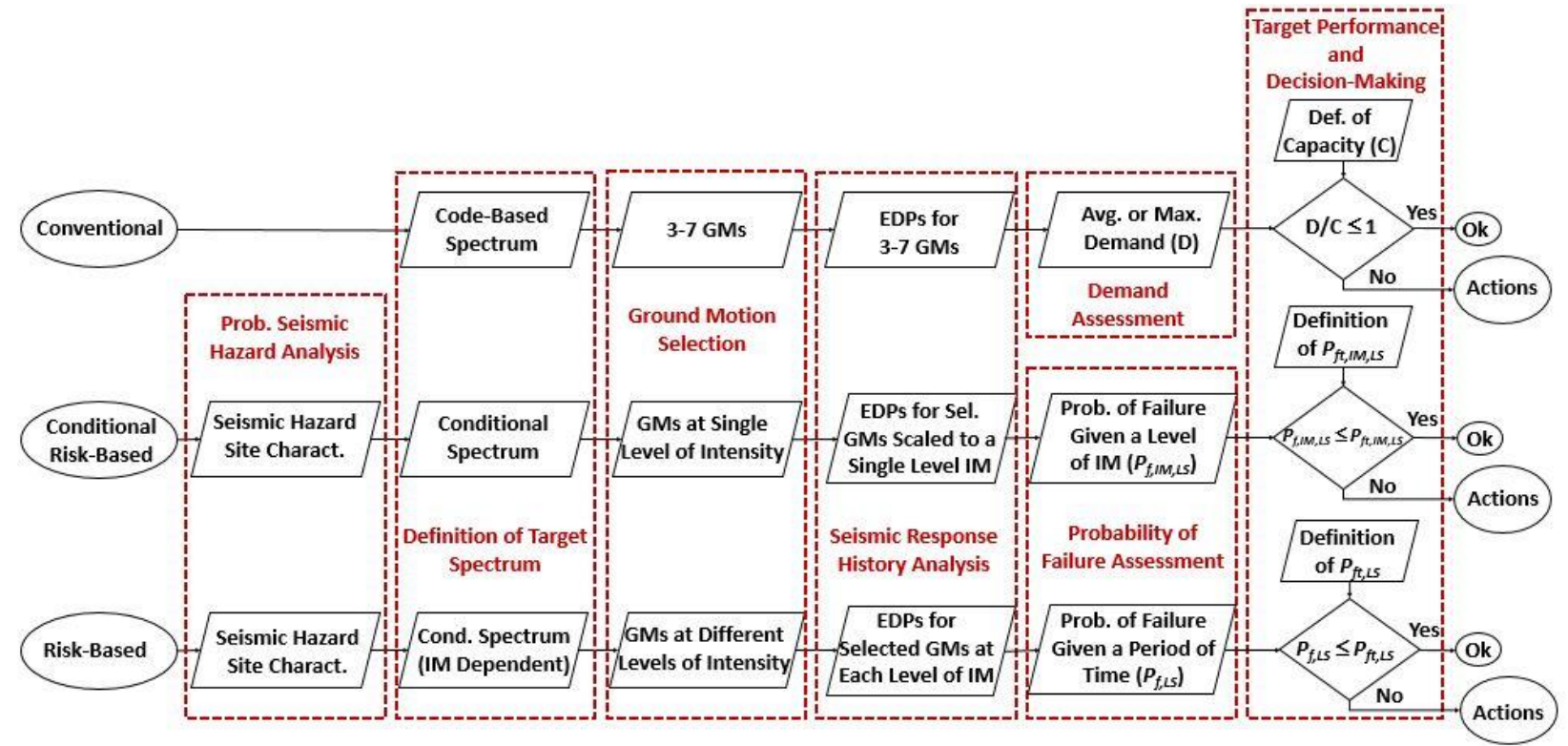

Fig. 12. The workflow of the conventional decision model, conditional risk-based decision model, and risk- 
This paper was published in Engineering Structures. Please cite it as:

Caprinozzi S, Dolšek M. Seismic performance assessment of non-code-conforming and code-conforming supporting structures of elevated tanks using conventional and risk-based decision models. Engineering structures, 2021, 227, 111469, https://doi.org/10.1016/j.engstruct.2020.111469,

DOI: 10.1016/j.engstruct.2020.111469.

based decision model.

The conventional decision model allows the user to use the code-based spectra directly and to select at least three ground motions [13]. Seven ground motions were considered in the case study. The demand used in the decision-making process was estimated by an average value rather than the maximum of engineering demand parameters resulting from the seismic response history analyses of seven ground motions (clause 4.3.3.4.3(3) of Eurocode [13]).

The conditional risk-based decision model and the risk-based decision model require more precise information about probabilistic seismic hazard analysis because the conditional spectrum defines the target spectrum. While the first approach requires the selection of ground motions at a specific seismic intensity to which the decision model is conditioned, the latter approach requires the selection of ground motions at multiple seismic intensities. In the present case study, 50 ground motions were selected for the conditional risk-based decision model, while the same number of ground motions was selected at different seismic intensity levels for the risk-based decision model.

The seismic response analysis, which is the simplest in the case of the conventional decision model, follows. The seismic response analysis for the other two decision models is equivalent to that from the conventional decision model but performed for significantly more ground motions. The conditional riskbased decision model provides a 'single stripe analysis'. The outcomes of the seismic response history analyses are represented by a multiple stripe analysis (MSA) [33] or incremental dynamic analysis (IDA) [34] for the risk-based model. In the present case study, the MSA was adopted.

The split between the three decision models is introduced in the next process, which involves the demand assessment and probability of failure assessment, respectively, in the case of the conventional decision model and the other decision models. For the conventional decision model, the demand is characterised by the mean values of the engineering demand parameters. However, in the case of conditional riskbased and risk-based decision models, the outcomes of the probability of failure assessment process are, respectively, the probability of exceeding a limit state for a given seismic intensity level, $P_{f, I M, L S}$, and the probability of exceeding a limit state for a given period, $P_{f, L S}$. The $P_{f, I M, L S}$ was calculated simply as the ratio between the ground motions that cause the exceedance of the LS $\left(n_{L S}\right)$ and the total number of the selected ground motions $\left(n_{G M}\right) . P_{f, L S}$ can be calculated by the conventional risk equation $[33,35,36] \mathrm{Eq}$. (1):

$\lambda=\int_{0}^{\infty} P(C \mid I M=i m) \cdot\left|\frac{d H(i m)}{d(i m)}\right| \cdot d(i m)$

where $\lambda$ is the rate of exceedance of the selected limit state, im is the value of random variable IM representing the seismic intensity measure, $P(C \mid I M=i m)$ is the probability of exceeding a designed LS given IM equalling $i m$, and $H(\mathrm{im})$ is the hazard function of the site of interest. Note that $\lambda$ is practically equal to the probability of failure for one year, $P_{f, L S}$. This statement is valid for the low values of $\lambda$, which is the case when it corresponds to the exceedance of near-collapse limit state. Under the assumption of the linearisation of the hazard function in log-domain, Eq. (1) can be represented in the closed-form solution [33,35], as presented in Eq. (2):

$\lambda=k_{0}\left(\tilde{S}_{a}\right)^{-k} \cdot e^{0.5 \cdot k^{2} \cdot \beta^{2}}$ 
This paper was published in Engineering Structures. Please cite it as:

Caprinozzi S, Dolšek M. Seismic performance assessment of non-code-conforming and code-conforming supporting structures of elevated tanks using conventional and risk-based decision models. Engineering structures, 2021, 227, 111469, https://doi.org/10.1016/i.engstruct.2020.111469,

DOI: 10.1016/j.engstruct.2020.111469.

where $k$ is the slope of the linear approximation of the hazard function in the log-domain, and $k_{0}$ is its intercept, $\tilde{S}_{a}$ is the median value of the IM that causes the exceedance of LS, and $\beta$ is the corresponding standard deviation of the natural logarithms of the IM which causes the exceedance of the LS.

The differentiation of the demand in the case of the three decision models is reflected in the target performance. The capacity $(C)$ in the case of the conventional decision model is defined by the engineering demand parameter associated with the exceedance of a limit state of interest. Because the demand in the other two decision models is expressed by the probability, it is necessary to define the target performance with the target probability.

For the conditional risk-based decision model and the limit state of interest, the target performance is defined using the target probability of exceeding the limit state $\left(P_{f, I M, L S}\right)$. The limit state of interest of this study is the NC limit state, and the level of seismic intensity corresponds to the return period of 2475 years as defined in Eurocode 8-3 [37]. For $P_{f t, I M, L S}$, we refer to ASCE/SEI 7-10 [6], which provides a threshold in terms of probability of exceeding different limit states according to their consequences for a maximum credible earthquake (MCE). MCE is 'the most severe earthquake effects considered by this standard'. In more detail, an MCE can be defined in two ways: with adjustment to target collapse risk $\left(\mathrm{MCE}_{\mathrm{R}}\right)$ and without adjustments to target risk $\left(\mathrm{MCE}_{\mathrm{G}}\right) . \mathrm{MCE}_{\mathrm{R}}$ is calculated via an iterative procedure starting from a collapse fragility function with assumed dispersion and hazard functions for the site of interest. $\mathrm{MCE}_{\mathrm{G}}$ ground motion is obtained from mean hazard curves for the site of interest considering the mean annual frequency of 1 in 2475 years, which corresponds to a probability of exceeding of $2 \%$ in 50 years [38,39]. Moreover, ASCE/SEI 7-10 defines the design earthquake as 2/3 of $\mathrm{MCE}_{\mathrm{R}}$, while the target probability of exceeding a limit state given a designated level of seismic intensity $\left(P_{f t, I M}\right)$ primarily depends on the severity of the limit state. The ASCE/SEI 7-10 accounts for two limit states: 'total or partial structural collapse' and 'failure that could result in endangerment of individual lives'. The corresponding target probability of exceeding the LS also depends on the risk category. In this study, the content of the tank is not hazardous. The collapse does not "cause a substantial economic impact and/or mass disruption of day-to-day civilian life' but neither to have 'a low risk to human life in the event of failure'. Thus, according to the risk category classification provided by the code, the most appropriate risk category for the investigated tank is risk category II [6]. Consequently, the allowable probability of exceeding a LS that can cause the 'total or partial structural collapse' in the case of MCE is $10 \%$. This value was adopted in this study for $P_{f t, I M, L S}$.

Concerning the target performance of the risk-based based decision model, some standards already address the target probability of failure given a period (e.g. [7]), while others, for instance, the working draft of new Eurocode [8], are still in the development process. In the state-of-practice, $P_{f t}$ basically depends on the definition of LS. Thus, the limit states of interest need to be selected. For this study, the near-collapse limit state was selected to be verified. A similar limit state is also assigned by ANS 2.26 [40] to units related to seismic design category 2 , which is the category to which the investigated tanks are assigned because the content of the tank is not hazardous. Consequently, the target probability of exceeding the NC limit state for one year and 50 years is equal to $4 \cdot 10^{-4}$ and $2 \%$, respectively. The limit state and the corresponding target probability of exceeding are thus consistent with ASCE 43-05 [7] and compatible with the draft of the new Eurocode [8], which informatively defines a target probability of exceeding the near-collapse limit state to $2 \cdot 10^{-4}$ (i.e. $1 \%$ in 50 years) for consequence class 2 (CC2) structures. However, the adopted $P_{f, L S}$ can be considered very high if compared to the target probability of exceeding less stringent limit states related to permanent load and variable loads [41]. Thus, the target reliability from Eurocode 0 cannot be directly comparable to target seismic risk. In a more general case, however, the definition of target probability of limit state exceeding due to earthquakes can be related 
This paper was published in Engineering Structures. Please cite it as:

Caprinozzi S, Dolšek M. Seismic performance assessment of non-code-conforming and code-conforming supporting structures of elevated tanks using conventional and risk-based decision models. Engineering structures, 2021, 227, 111469, https://doi.org/10.1016/j.engstruct.2020.111469,

DOI: $10.1016 / j$. engstruct.2020.111469.

to fatality risk or the performance of the system (e.g. [42-46]) which was, not addressed in the study presented in the paper for simplicity reasons.

\subsection{Ground motions for the performance assessment using three decision models}

Ground motions for the performance assessment using the conventional decision model were selected according to Eurocode 8, as discussed in Section 4.1. A set of seven ground motions was selected through Rexel software by Iervolino et al. [47], based on target spectrum matching. The software searches for pairs of the two horizontal components of ground motions. In the present case, seven pairs were selected for a total of fourteen records. In the selection procedure, the average spectrum of the fourteen records was matched to the target spectrum. This procedure was found to be adequate in Iervolino et al. [48] concerning Eurocode provisions [31], even if it is not fully compliant with the Eurocode.

The target spectrum was selected as the Type 1 spectrum of the Eurocode provisions and normalised to PGA $=1 \mathrm{~g}$ (from the hazard curve at $\mathrm{T}_{\mathrm{R}}=2475$ years). The spectra of the selected records, the corresponding mean spectrum, and the target spectrum are presented in Fig. 13.

The most common target spectrum for the ground-motion selection is the uniform hazard spectrum (UHS). However, the UHS was found to be unsuitable as it conservatively implies large-amplitude spectral values at all periods within a single ground motion [49]. Hence, in this paper, the conditional spectrum approach is used for ground motion selection in the case of conditional risk-based and riskbased decision models. Ground motions were selected according to the algorithm proposed by Jayaram et al. [50]. The PGA was assumed as the seismic intensity measure IM.

Because the fragility analysis was performed by multiple-stripe analysis [33], different sets of ground motions were selected for different levels of PGA. Note that twenty-five PGA intervals from $0.1 \mathrm{~g}$ to 4 $\mathrm{g}$ were identified, spaced every $0.1 \mathrm{~g}$ from 0.1 to $1 \mathrm{~g}$, and then, every $0.2 \mathrm{~g}$. Fifty GMs were selected using the conditional spectrum approach (CS) computed at each PGA interval up to $1 \mathrm{~g}$.

For the PGA steps greater than $1 \mathrm{~g}$, the set of GMs corresponding to $1 \mathrm{~g}$ was scaled up to $4 \mathrm{~g}$. CS was defined using the results of the SHARE project by Woessner et al. [18] and based on the results of the seismic hazard disaggregation for the site.

Note that all GMs were selected from the NGA strong ground motion database [51] and the RESORCE [52] database. For example, Fig. 14 shows the spectra of the selected ground motions in the case of PGA $=1 \mathrm{~g}$, which correspond to a returning period of 2475 years, the corresponding mean spectrum and the target spectrum. The magnitude and the source-to-site distance of the events of the selected GM are within $4.5-7.5$ and $5-50 \mathrm{~km}$, respectively. Note that this set of ground motions was also used in the seismic response analysis performed in the case of the conditional risk-based decision model. 
This paper was published in Engineering Structures. Please cite it as:

Caprinozzi S, Dolšek M. Seismic performance assessment of non-code-conforming and code-conforming supporting structures of elevated tanks using conventional and risk-based decision models. Engineering structures, 2021, 227, 111469, https://doi.org/10.1016/j.engstruct.2020.111469,

DOI: 10.1016/j.engstruct.2020.111469.

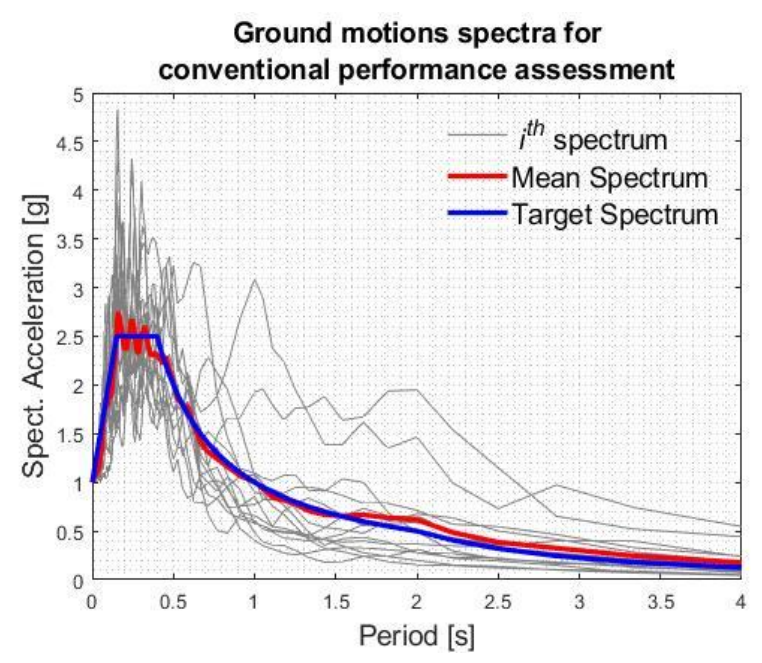

Fig. 13. Acceleration spectra of selected ground motions for the two horizontal components, the corresponding mean and the target spectrum for conventional performance assessment.

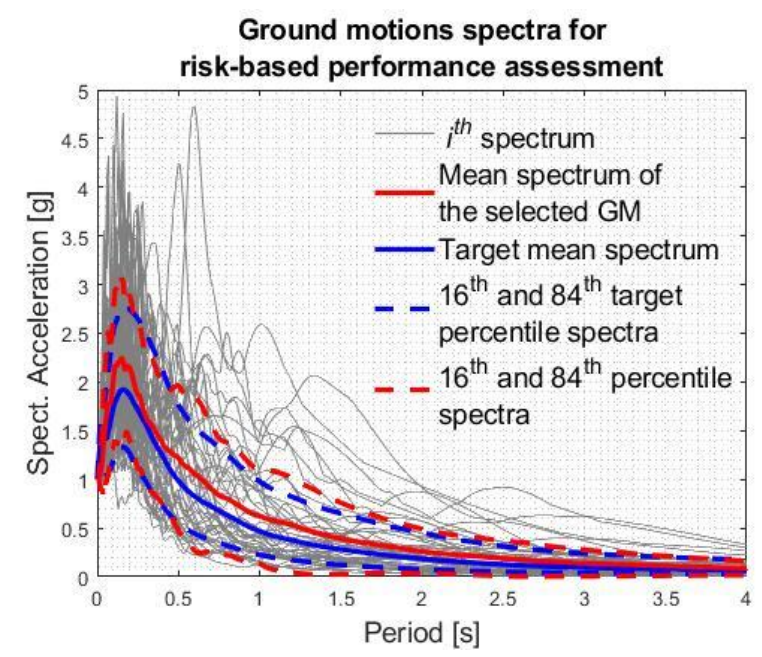

Fig. 14. Ground motion spectra, mean, and target spectrum at PGA $=1 \mathrm{~g}$, which corresponds to a return period of 2475 years.

\subsection{Performance assessment of the investigated tanks by the conventional decision model}

The seismic performance of the non-code-conforming tanks and code-conforming tanks was evaluated by the conventional decision model presented in Section 4.1.

Based on the results of response history analyses of non-code-conforming tanks, which were determined with consideration of the seven ground motions (Section 4.2), it was observed that the mean value of the demand-to-capacity ratio of the non-code-conforming tank was greater than 1 for a full $(90 \%$ filling level) or empty ( $0 \%$ filling level) tank (Fig. 15 (a)). By considering the full or empty tank, it can be concluded that the seismic performance of the investigated non-code-conforming tank is not acceptable. However, the seismic performance of the code-conforming tanks was acceptable. The demand-tocapacity ratios were significantly less than one for all considered tank filling levels (Fig. 15 (b)). 
This paper was published in Engineering Structures. Please cite it as:

Caprinozzi S, Dolšek M. Seismic performance assessment of non-code-conforming and code-conforming supporting structures of elevated tanks using conventional and risk-based decision models. Engineering structures, 2021, 227, 111469, https://doi.org/10.1016/j.engstruct.2020.111469,

DOI: 10.1016/j.engstruct.2020.111469.

Because the demand-to-capacity ratios of the code-conforming tank are significantly less than 1, It could appear that the supporting structure of the code-conforming tanks is overdesigned. Such interpretation might be valid if only the conventional decision model is used for the evaluation of the performance assessment of structures. However, before making conclusions, we will first present the results of the evaluation of the seismic performance assessment of the investigated tanks using the conditional riskbased and risk-based decision models.
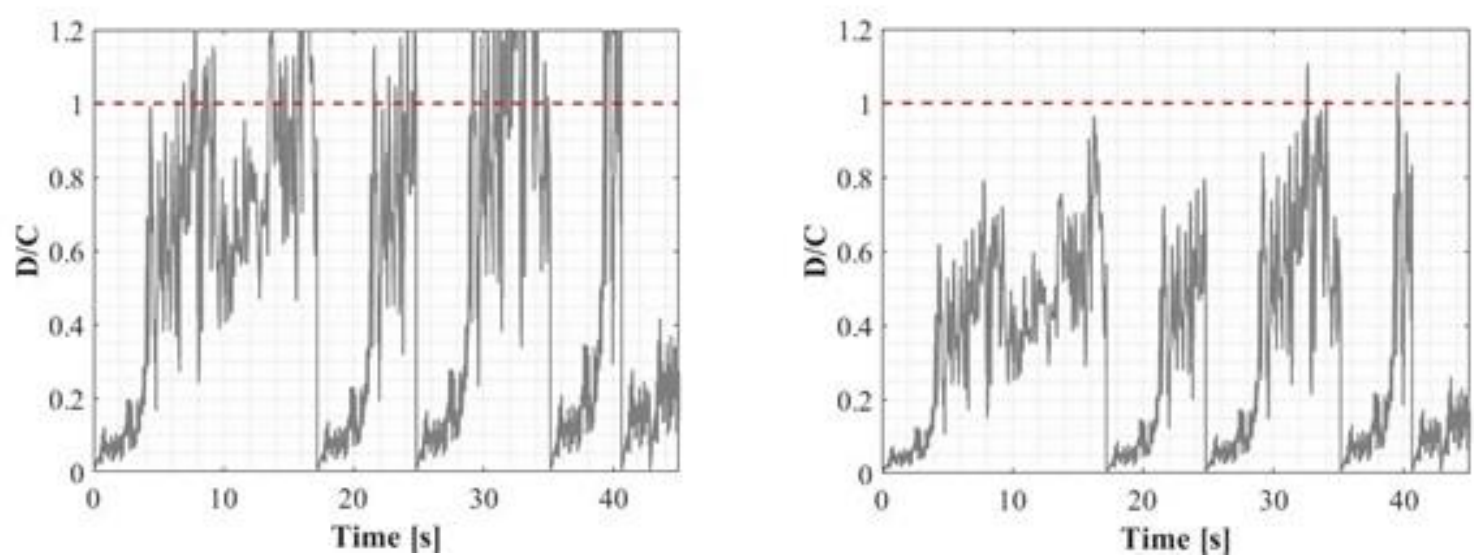

(a)
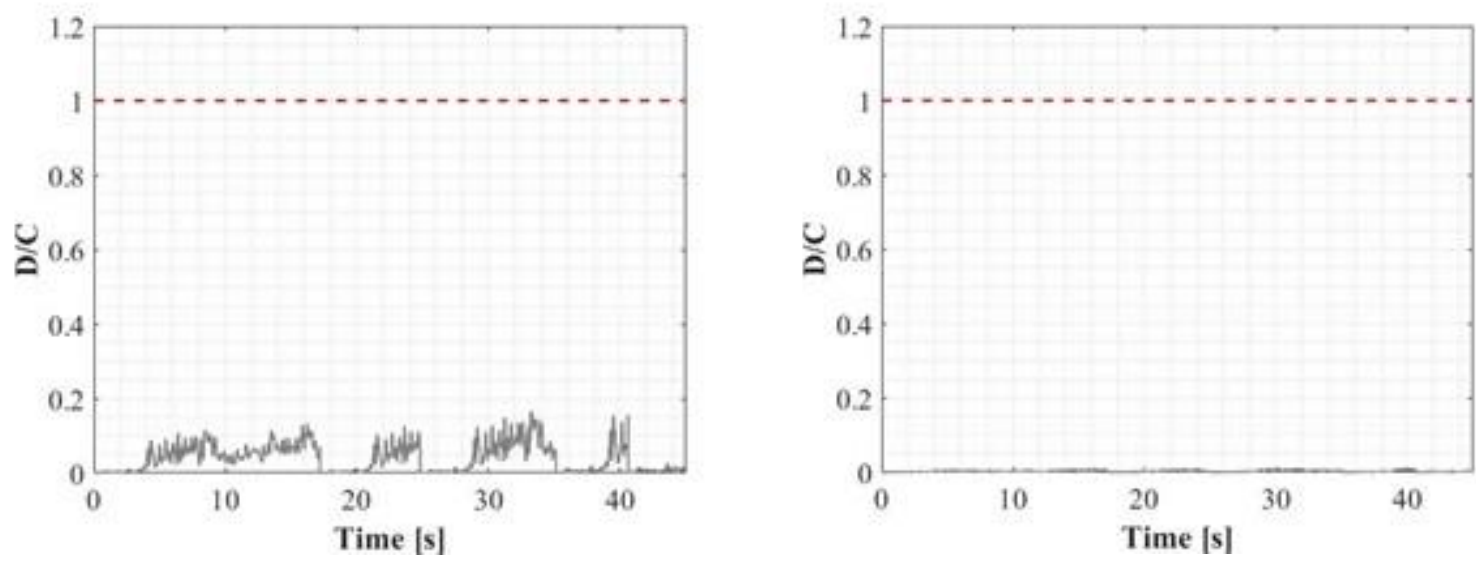

(b)

Fig. 15. The demand-to-capacity ratio in the columns based on the averaging results of the seven ground motions in the case of (a) non-code-conforming tank and (b) code-conforming tank. Results are presented for full tanks (90\% filling level, left) and empty tanks (0\%, right).

\subsection{Performance assessment of the investigated tanks by the conditional risk-based and risk-based decision models}

The seismic performance assessment of the investigated tanks was evaluated using the conditional riskbased model and the risk-based decision model (Section 4.1). The intermediate results of the latter decision model are fragility functions, which were evaluated by MSA using ground motions presented in Section 4.2 in this study. Note that ground motions for the stripe corresponding to PGA $=1 \mathrm{~g}$ (Section 4.2) were used in the case of the conditional risk-based decision model because this intensity level 
This paper was published in Engineering Structures. Please cite it as:

Caprinozzi S, Dolšek M. Seismic performance assessment of non-code-conforming and code-conforming supporting structures of elevated tanks using conventional and risk-based decision models. Engineering structures, 2021, 227, 111469, https://doi.org/10.1016/i.engstruct.2020.111469,

DOI: 10.1016/j.engstruct.2020.111469.

corresponds to the return period of 2475 years. The considered filling levels of the tanks did not include the empty tank, because in this case, the scaling factors for the ground motions to reach the structural collapse would be too high.

The MSA was performed to evaluate the number of ground motions that caused the exceedance of the NC limit state. The parameters of the fragility function, i.e. the median PGA causing the exceedance of the NC limit state, $\theta$, and the corresponding dispersion, $\beta$, were calculated by maximising the logarithm of the likelihood function in Eq. (3) [53]:

$\{\hat{\theta}, \hat{\beta}\}=\operatorname{argmax}_{\theta, \beta} \sum_{j=1}^{m}\left\{\ln \left(\begin{array}{c}n_{j} \\ z_{j}\end{array}\right)+z_{j} \ln \Phi\left(\frac{\ln \frac{x_{j}}{\theta}}{\beta}\right)+\left(n_{j}-z_{j}\right) \ln \left(1-\Phi\left(\frac{\ln \frac{x_{j}}{\theta}}{\beta}\right)\right)\right\}$

where $m$ represents the number of stripes in MSA, $n_{j}$ is the number of ground motions at intensity $j, z_{j}$ is the number of ground motions exceeding NC LS at stripe $j$, and $x_{j}$ is the seismic intensity at stripe $j$. The resulting estimators (i.e. $\hat{\theta}$ and $\hat{\beta}$ ) are presented in Table 7 for all investigated tanks and all considered tank filling levels. Note that for the sake of brevity they are termed $\theta$ and $\beta$.

Fig. 16 presents the results of MSA in the case of $90 \%$ of the filling level for non-code-conforming and code-conforming tanks, respectively. Each dot on the right-hand side of the LS dashed line represents the aforementioned $z_{j}$. Note that in the case of the non-code-conforming tank, for PGA=1 $\mathrm{g}, z_{j}$ corresponds to $n_{j}$, which is the total amount of GM at that stripe (50 GM).

The multiple stripe analysis was performed by scaling ground motions to PGA $=4 \mathrm{~g}$, which required unrealistically high scaling factors of recorded ground motions. Thus the fragility functions were calculated by cutting off MSA results at PGA $=2 \mathrm{~g}$ for $90 \%$ of the filling level. Such an approach make it possible to check the bias in the evaluation of the fragility functions and the corresponding risk. However, no changes were observed in the fragility function of the non-code-conforming tank. For the code-conforming tank, the median PGA causing exceedance of NC limit state and the corresponding dispersion as presented in Table 7 were reduced, respectively, for about $10 \%$ and $20 \%$. This reduction caused a slight anticlockwise rotation of the fragility function of the code-conforming tank around the point characterised by the probability of exceeding of about 0.16 . However, such modification of fragility function causes only a minor impact on the annual probability of failure, as discussed elsewhere [54]. In this particular case, the probability of exceeding was estimated to $1.6 \cdot 10^{-4}$ per year for maximum PGA cut off at $2 \mathrm{~g}$ instead of $1.7 \cdot 10^{-4}$ per year for PGA considered to $4 \mathrm{~g}$. Thus, it was decided to use the fragility functions based on MSA associated with high scaling of ground motions, which may not be the case for some other structures or even some other tanks.

The corresponding fragility functions are presented in Fig. 17 for all the investigated tanks and different tank filling levels. Reducing the tank filling level shifts the fragility functions to the right. This shift means the vulnerability of the supporting structure of tanks can be significantly reduced when the tanks are empty. However, this does not mean the tank is not vulnerable.

Table 7. Median PGA causing the exceedance of the NC limit state, $\theta$, and the corresponding dispersion, $\beta$, for different filling levels of non-code-conforming and code-conforming tanks.

\begin{tabular}{ccccc}
\hline $\begin{array}{c}\text { Tank filling } \\
\text { level }\end{array}$ & $\begin{array}{c}\text { Non-code- } \\
\text { conforming }\end{array}$ & Code-conforming & $\begin{array}{c}\text { Non-code- } \\
\text { conforming }\end{array}$ & Code-conforming \\
\hline $90 \%$ (full) & 0.49 & 0.57 & 0.32 & 2.05 \\
\hline
\end{tabular}


This paper was published in Engineering Structures. Please cite it as:

Caprinozzi S, Dolšek M. Seismic performance assessment of non-code-conforming and code-conforming supporting structures of elevated tanks using conventional and risk-based decision models. Engineering structures, 2021, 227, 111469, https://doi.org/10.1016/j.engstruct.2020.111469,

DOI: 10.1016/j.engstruct.2020.111469.

\begin{tabular}{lllll}
$80 \%$ & 0.53 & 0.54 & 0.34 & 2.23 \\
$70 \%$ & 0.52 & 0.52 & 0.35 & 2.51 \\
$60 \%$ & 0.50 & 0.48 & 0.40 & 2.75 \\
$50 \%$ & 0.48 & 0.47 & 0.45 & 3.11 \\
$40 \%$ & 0.44 & 0.42 & 0.55 & 3.50 \\
$30 \%$ & 0.40 & 0.36 & 0.64 & 3.79 \\
$20 \%$ & 0.37 & 0.26 & 0.69 & 4.22 \\
\hline
\end{tabular}

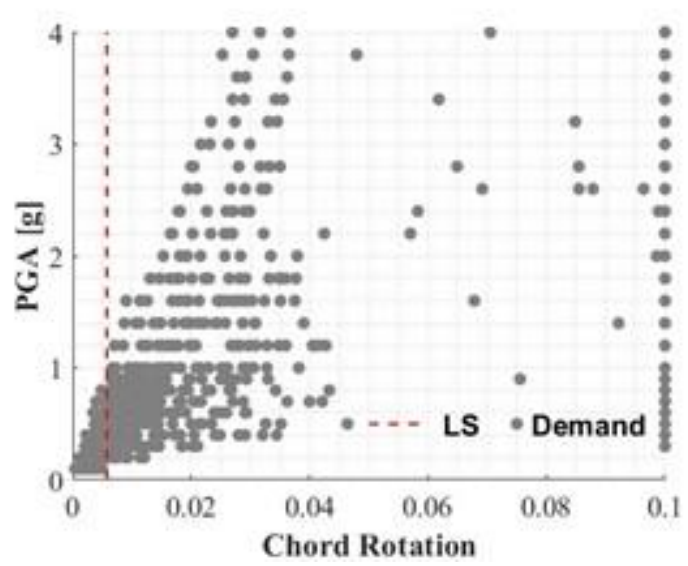

(a)

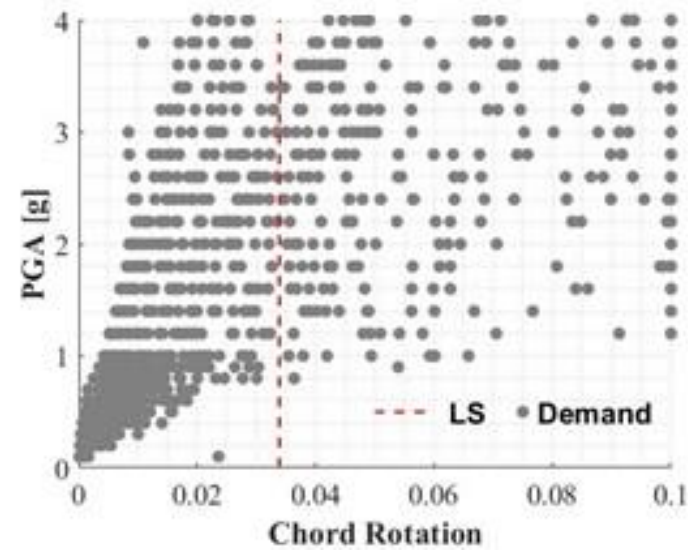

(b)

Fig. 16. MSA results for (a) the non-code-conforming and (b) the code-conforming tank. Results are presented for full tanks (90\% filling level).

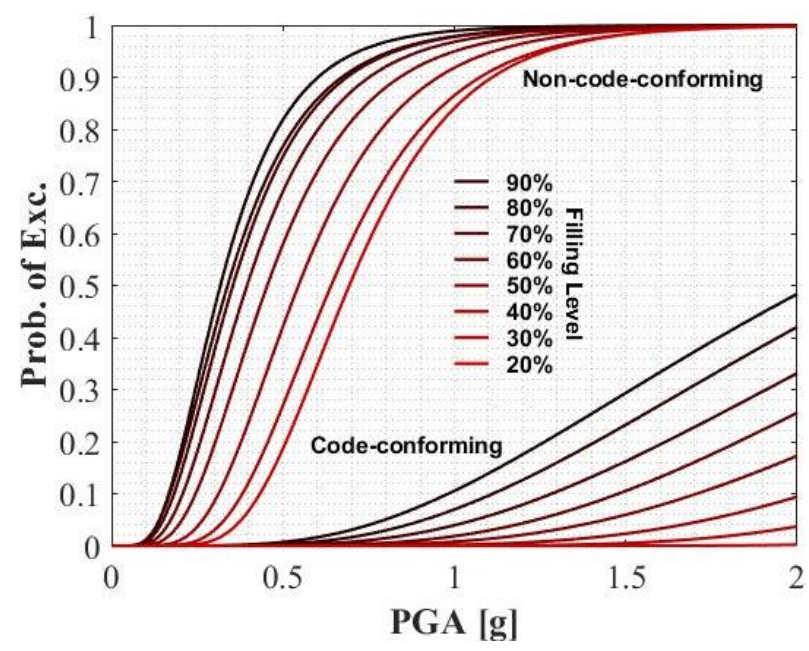

Fig. 17. Fragility curves for the non-code-conforming tank and code-conforming tank designed for DCH.

Fragility curves are presented for different tank filling levels.

The ratios between the median PGA capacities causing the exceedance of the NC limit state in the case of the full and almost empty tank (i.e. 20\% tank filling level) is about 2. The dispersion of PGA causing the NC limit state is in the case of the full tank about 0.5 , regardless of the type of the tank. However, for low levels of tank filling (e.g. 20-40\%), $\beta$ is reduced to about 0.4 . Quite similar trends for the $\beta$ can be observed in the case of code-conforming tanks. As the filling level reduces, the dispersion reduces, too. The reason for this behaviour is twofold. First, by reducing the impulsive mass, the period is closer to zero. As a consequence, the dispersion of spectral acceleration reduces. Subsequently, this dispersion 
This paper was published in Engineering Structures. Please cite it as:

Caprinozzi S, Dolšek M. Seismic performance assessment of non-code-conforming and code-conforming supporting structures of elevated tanks using conventional and risk-based decision models. Engineering structures, 2021, 227, 111469, https://doi.org/10.1016/i.engstruct.2020.111469,

DOI: 10.1016/j.engstruct.2020.111469.

causes a reduction of dispersion of spectral acceleration, causing exceedance of limit state. Note that a smaller dispersion reveals an increase in the efficiency of the IM, as discussed by Jankovic et al. [55].

To facilitate the interpretation of the results, the ratios between the PGA corresponding to returning period of 475 years $\left(\theta_{475}=0.5 \mathrm{~g}\right)$ and the median PGA causing the NC limit state are presented in Table 8 . These ratios are not constant, and they are significantly greater than 1 in some cases of non-codeconforming tanks (see $\theta_{475} / \theta>1$ Table 8 ). This means that the probability of exceeding the NC limit state in the case of the non-code-conforming tank is greater than 50\%, if the tank filling level is more than $50 \%$, and in the case of seismic action corresponding to returning period of 475 years.

The performance of the code-conforming tanks is significantly better. The observed ratios $\theta_{475} / \theta$ are in the interval from about 0.3 to 0.1 . The values of $\theta$ for code-conforming tanks are very high (from 2 to 4 $\mathrm{g})$. The latest value of $\theta$ is even greater than the largest recorded PGA during the strongest earthquakes. However, it cannot be excluded that the NC limit state is exceeded for significantly lower values of PGA (see Fig. 16).

According to the first risk-based decision model, the performance of the tank for the NC limit state is considered acceptable if there is less than $10 \%$ probability of exceeding the NC limit state at PGA $=1$ g (i.e. returning period of 2475 years), which is, in this particular example, 200\% of the PGA corresponding to return period of 475 years. Table 9 summarises the probability of exceeding the NC limit state calculated according to the single stripe analysis (SSA) referring to the PGA $=1 \mathrm{~g}$ (Fig. 16) as defined in Section 4.1. The presented probabilities are based on the ratio between the number of ground motions causing collapse and the number of all ground motions considered in the SSA.

The results in Table 9 show that the performance of the non-code-conforming tank is not acceptable, because the resulting probability of exceeding the $\mathrm{NC}$ limit state given PGA $=1 \mathrm{~g}$ is significantly greater than $10 \%$ even when the tank is only $20 \%$ full (see Table 9). Regarding the code-conforming tank, in the case of lower filling levels, the probabilities of exceedance of the NC limit state given PGA $=1 \mathrm{~g}$ are negligible. The highest probability is observed in the case of $90 \%$ of the filling level, which is even greater than $10 \%$.

The basic result of the risk analysis is the probability of exceeding a designated limit state for one year $\left(P_{f, L S}\right)$, which can be calculated by a conventional risk equation (Eq. (1)). The results of the risk analysis in terms of probability of exceeding the NC limit state in one year are presented in Table 10. In addition, the probability of exceeding the NC limit state in 0 years $\left(P_{f, L S, 50}\right)$ is also presented. The corresponding acceptable probabilities for a period of 1 and 50 years are $2 \cdot 10^{-4}$ and $1 \%$, respectively, as defined in Section 4.1.

The risk of exceedance of the NC limit state in the case of the non-code-conforming tank is about $30 \%$ in 50 years if the tank is full. Such a risk is excessively high and requires immediate action to reduce it. However, the performance of the code-conforming tank can be considered acceptable, but the probability of exceeding the NC limit state in the case of the code-conforming tank is almost equal to the acceptable probability (i.e. $2 \cdot 10^{-4}$ in one year, $1 \%$ in 50 years). Thus, the supporting structure is not overdesigned, based on the conventional decision model and the risk-based decision model that employs the probability of exceeding the NC limit state for a given seismic intensity.

Table 8. The ratio between PGA corresponding to the return period of 475 years $\left(\theta_{475}\right)$ and the median PGA causing the exceedance of the NC limit state. 
This paper was published in Engineering Structures. Please cite it as:

Caprinozzi S, Dolšek M. Seismic performance assessment of non-code-conforming and code-conforming supporting structures of elevated tanks using conventional and risk-based decision models. Engineering structures, 2021, 227, 111469, https://doi.org/10.1016/i.engstruct.2020.111469,

DOI: 10.1016/j.engstruct.2020.111469.

\begin{tabular}{ccc}
\hline & Non-code-conforming & Code-conforming \\
\hline $90 \%$ (full) & 1.56 & 0.24 \\
$80 \%$ & 1.47 & 0.22 \\
$70 \%$ & 1.43 & 0.20 \\
$60 \%$ & 1.25 & 0.18 \\
$50 \%$ & 1.11 & 0.16 \\
$40 \%$ & 0.91 & 0.14 \\
$30 \%$ & 0.78 & 0.13 \\
$20 \%$ & 0.72 & 0.12 \\
\hline
\end{tabular}

Table 9. Probability of exceeding the near-collapse LS for the PGA corresponding to a returning period of 2475 years.

\begin{tabular}{ccc}
\hline Tank filling level & $\begin{array}{c}\text { Probability of Exceeding the LS given PGA = 1.0 g }\left(\boldsymbol{P}_{f, I M, L S}\right) \\
\text { Non-code-conforming } \\
\text { SSA }\end{array}$ & $\begin{array}{c}\text { Code-conforming } \\
\text { SSA }\end{array}$ \\
\hline $90 \%$ (full) & $100 \%$ & $14 \%$ \\
$80 \%$ & $98 \%$ & $4 \%$ \\
$70 \%$ & $96 \%$ & {$[-]$} \\
$60 \%$ & $98 \%$ & {$[-]$} \\
$50 \%$ & $94 \%$ & {$[-]$} \\
$40 \%$ & $88 \%$ & {$[-]$} \\
$30 \%$ & $84 \%$ & {$[-]$} \\
$20 \%$ & $80 \%$ & {$[-]$} \\
\hline
\end{tabular}

Table 10. Probability of Exceedance of LS given a period.

\begin{tabular}{ccccc}
\hline & \multicolumn{3}{c}{$\begin{array}{c}\text { Probability of Exceeding the LS given one year and 50 years } \\
\text { Non-code-conforming }\end{array}$} & \multicolumn{2}{c}{$\begin{array}{c}\text { Code-conforming } \\
\text { Tank }\end{array}$} & $\boldsymbol{P}_{f, L S}$ & $\boldsymbol{P}_{f, L S, 50}$ & $1.7 \cdot 10^{-4}$ & $\boldsymbol{P}_{f, L S, 50}$ \\
\hline $90 \%$ (full) & $7.5 \cdot 10^{-3}$ & $31.4 \%$ & $1.3 \cdot 10^{-4}$ & $0.9 \%$ \\
$80 \%$ & $7.1 \cdot 10^{-3}$ & $29.7 \%$ & $8.5 \cdot 10^{-5}$ & $0.6 \%$ \\
$70 \%$ & $6.4 \cdot 10^{-3}$ & $27.5 \%$ & $5.8 \cdot 10^{-5}$ & $0.4 \%$ \\
$60 \%$ & $5.2 \cdot 10^{-3}$ & $23.0 \%$ & $3.9 \cdot 10^{-5}$ & $0.3 \%$ \\
$50 \%$ & $4.0 \cdot 10^{-3}$ & $18.0 \%$ & $2.4 \cdot 10^{-5}$ & $0.2 \%$ \\
$40 \%$ & $2.6 \cdot 10^{-3}$ & $12.3 \%$ & $1.5 \cdot 10^{-5}$ & $0.1 \%$ \\
$30 \%$ & $1.8 \cdot 10^{-3}$ & $8.6 \%$ & $8.8 \cdot 10^{-6}$ & $0.1 \%$ \\
$20 \%$ & $1.4 \cdot 10^{-3}$ & $6.9 \%$ & & $0.04 \%$ \\
\hline
\end{tabular}

\section{CONCLUSIONS}

The damage to the almost-full and almost-empty tanks observed during the Kocaeli earthquake could be adequately simulated by the simplified non-linear models of the tanks, as presented and discussed in the paper. However, the simulations of seismic response of tanks, as considered in the study, are based on several assumptions. The study focused only on the seismic performance of the supporting structure against the NC limit state. Thus, the study's observations and conclusions may be partially affected by 
This paper was published in Engineering Structures. Please cite it as:

Caprinozzi S, Dolšek M. Seismic performance assessment of non-code-conforming and code-conforming supporting structures of elevated tanks using conventional and risk-based decision models. Engineering structures, 2021, 227, 111469, https://doi.org/10.1016/i.engstruct.2020.111469,

DOI: 10.1016/j.engstruct.2020.111469.

the definition of the limit states and the corresponding target probabilities of exceedance, the definition of which is currently a topic of discussion (e.g. [8]).

The results of the study also proved that the seismic performance of the non-code-conforming support structure of the elevated tank is not acceptable, regardless of the decision model used. Such an outcome indicated the need to urgently retrofit cases like the non-code-conforming tank.

The opposite can be concluded for the code-conforming tank, for which the seismic performance is acceptable, except in the case of the full tank evaluated using the conditional risk-based decision model. In this case, the probability of exceeding the near-collapse limit state was slightly higher than the target probability. This finding may be the consequence of the relatively simple evaluation of the probability of exceeding the near-collapse limit state given the seismic intensity. If this probability were evaluated from the fragility function, then the performance of the code-conforming tank would be acceptable even when evaluated using the conditional risk-based decision model.

Comparing the results of the three decision models applied to the code-conforming tank showed that the conventional decision model is not well calibrated to the target risk. The $\mathrm{D} / \mathrm{C}$ ratios were significantly lower than the unity, which makes the support structure appear to be overdesigned. The results of the risk-based decision model proved that such a conclusion would be incorrect because the estimated probability of failure of the code-conforming tank was slightly less than the target value, which was set equal to $1 \%$ in 50 years. For this reason, the risk-based metrics provide much more information. However, they are computationally more demanding, especially in the case of the risk-based decision model, and can be considered only by using simplified non-linear models.

\section{ACKNOWLEDGEMENT}

This research is part of the XP-RESILIENCE project, which is funded by the European Union's Horizon 2020 research and innovation program under the Marie Sklodowska-Curie grant agreement No. 721816.

\section{REFERENCES}

[1] Di Sarno L, Karagiannakis G. Petrochemical steel pipe rack: Critical assessment of existing design code provisions and a case-study. Int J Steel Struct 2019. https://doi.org/10.1007/s13296019-00280-w.

[2] Paolacci F, Giannini R, De Angelis M. Seismic response mitigation of chemical plant components by passive control techniques. J Loss Prev Process Ind 2013;26:924-35. https://doi.org/10.1016/j.jlp.2013.03.003.

[3] Bernier C, Padgett JE. Buckling of aboveground storage tanks subjected to storm surge and wave loads. Eng Struct 2019;197:109388. https://doi.org/10.1016/j.engstruct.2019.109388.

[4] Chiang Y-C, Guzey S. Dynamic analysis of aboveground open-top steel tanks subjected to wind loading. Eng Struct 2019;198:109496. https://doi.org/10.1016/j.engstruct.2019.109496.

[5] Vathi M, Karamanos SA, Kapogiannis IA, Spiliopoulos K V. Performance Criteria for Liquid Storage Tanks and Piping Systems Subjected To Seismic Loading. J Press Vessel Technol 2017:1-12. https://doi.org/10.1115/1.4036916.

[6] ASCE. Minimum Design Loads for Buildings and Other Structures. American Society of Civil Engineers; 2010.

[7] ASCE. Seismic Design Criteria for Structures, Systems, and Components in Nuclear Facilities. American Society of Civil Engineers; 2005. 
This paper was published in Engineering Structures. Please cite it as:

Caprinozzi S, Dolšek M. Seismic performance assessment of non-code-conforming and code-conforming supporting structures of elevated tanks using conventional and risk-based decision models. Engineering structures, 2021, 227, 111469, https://doi.org/10.1016/j.engstruct.2020.111469,

DOI: 10.1016/j.engstruct.2020.111469.

[8] CEN. CEN/TC 250/SC 8 Eurocode 8: - Design of structures for earthquake resistance - Part 11: General rules and seismic action. Brussels: European Committee for Standardisation; 2019.

[9] Salzano E, Iervolino I, Fabbrocino G. Seismic risk of atmospheric storage tanks in the framework of quantitative risk analysis. J Loss Prev Process Ind 2003;16:403-9. https://doi.org/10.1016/S0950-4230(03)00052-4.

[10] Phan HN, Paolacci F, Alessandri S. Fragility Analysis Methods for Steel Storage Tanks in Seismic Prone Areas. Vol 8 Seism Eng 2016;00032:V008T08A023. https://doi.org/10.1115/PVP2016-63102.

[11] Lazar Sinković N, Brozovič M, Dolšek M. Risk-based seismic design for collapse safety. Earthq Eng Struct Dyn 2016;45:1451-71. https://doi.org/10.1002/eqe.2717.

[12] Sezen H, Whittaker AS. Seismic Performance of Industrial Facilities Affected by the 1999 Turkey Earthquake. J Perform Constr Facil 2006;20:28-36. https://doi.org/10.1061/(ASCE)0887-3828(2006)20:1(28).

[13] CEN. Eurocode 8: Design of structures for earthquake resistance - Part 1: General rules, seismic actions and rules for buildings. Brussels: European Committee for Standardisation; 2004.

[14] Girgin S. The natech events during the 17 August 1999 Kocaeli earthquake: Aftermath and lessons learned. Nat Hazards Earth Syst Sci 2011;11:1129-40. https://doi.org/10.5194/nhess-111129-2011.

[15] Özmen B. Isoseismal Map , Human Casualty And Building Damage Statistics Of The Izmit Earthquake Of August 17, 1999. Third Japan-Turkey Work. Earthq. Eng., 2000, p. 1-11.

[16] Phan HN, Paolacci F, Bursi OS, Tondini N. Seismic fragility analysis of elevated steel storage tanks supported by reinforced concrete columns. J Loss Prev Process Ind 2017;47:57-65. https://doi.org/10.1016/j.jlp.2017.02.017.

[17] CEN. Eurocode 8 - Design of structures for earthquake resistance - Part 4: Silos, tanks and pipelines. 2006.

[18] Woessner J, Laurentiu D, Giardini D, Crowley H, Cotton F, Grünthal G, et al. The 2013 European Seismic Hazard Model: key components and results. Bull Earthq Eng 2015;13:3553-96. https://doi.org/10.1007/s10518-015-9795-1.

[19] CSI. SAP2000 Integrated Software for Structural Analysis and Design 2011.

[20] McKenna F, Fenves GL. Open System for Earthquake Engineering Simulation (OpenSees) 2010. http://opensees.berkeley.edu.

[21] CEN. Eurocode 2: Design of concrete structures - Part 1-1: General rules and rules for buildings. Brussels: European Committee for Standardisation; 2004.

[22] Scott BD, Park R, Priestley MJN. Stress-Strain Behavior of Concrete Confined by Overlapping Hoops at Low and High Strain Rates. ACI J Proc 1982;79. https://doi.org/10.14359/10875.

[23] Filippou FC, Popov EP, Bertero V V. Effects of Bond Deterioration on Hysteretic Behavior of Reinforced Concrete Joints. Earthquake Engineering Research Center, University of California, Berkeley; 1983.

[24] Malhotra PK, Wenk T, Wieland M. Simple procedure for seismic analysis of liquid-storage tanks. Struct Eng Int J Int Assoc Bridg Struct Eng 2000;10:197-201. https://doi.org/10.2749/101686600780481509. 
This paper was published in Engineering Structures. Please cite it as:

Caprinozzi S, Dolšek M. Seismic performance assessment of non-code-conforming and code-conforming supporting structures of elevated tanks using conventional and risk-based decision models. Engineering structures, 2021, 227, 111469, https://doi.org/10.1016/j.engstruct.2020.111469,

DOI: 10.1016/j.engstruct.2020.111469.

[25] Setzler EJ, Sezen H. Model for the lateral behavior of reinforced concrete columns including shear deformations. Earthq Spectra 2008;24:493-511. https://doi.org/10.1193/1.2932078.

[26] Bentz EC. Sectional analysis of reinforced concrete members 2000:316.

[27] Elwood KJ, Moehle JP. Axial capacity model for shear-damaged columns. ACI Struct J 2005;102:578-87. https://doi.org/10.14359/14562.

[28] Phan HN, Paolacci F. Fluid-Structure Interaction Problems: an Application To Anchored and Unanchored Steel Storage Tanks Subjected To Seismic Loadings. Eur Conf Earthq Eng 2018:110 .

[29] Paolacci F, Reza MS, Bursi OS. Seismic analysis and component design of refinery piping systems. COMPDYN 2011, 3rd ECCOMAS Themat. Conf. Comput. Methods Struct. Dyn. Earthq. Eng., Corfu, Greece: 2011.

[30] Cozzani V, Salzano E. The quantitative assessment of domino effects caused by overpressure: Part I. Probit models. J Hazard Mater 2004;107:67-80. https://doi.org/10.1016/j.jhazmat.2003.09.013.

[31] CEN. Eurocode 8 Design of structures for earthquake resistance Part 2: Bridges. Brussels: European Committee for Standardisation; 2005.

[32] Bakalis K. Seismic risk assessment of liquid storage tanks via a nonlinear surrogate model 2017:2851-68. https://doi.org/10.1002/eqe.2939.

[33] Jalayer F, Cornell CA. Alternative non-linear demand estimation methods for probability-based seismic assessments. Earthq Eng Struct Dyn 2009;38:951-72. https://doi.org/10.1002/eqe.876.

[34] Vamvatsikos D, Fragiadakis M. Incremental dynamic analysis for estimating seismic performance sensitivity and uncertainty. Earthq Eng Struct Dyn 2010;39:141-63. https://doi.org/10.1002/eqe.935.

[35] McGuire RK. Seismic Hazard And Risk Analysis. Oakland: 2004.

[36] Lazar N, Dolšek M. Incorporating intensity bounds for assessing the seismic safety of structures: Does it matter? Earthq Eng Struct Dyn 2014;43:717-38. https://doi.org/10.1002/eqe.2368.

[37] CEN. Eurocode 8: Design of structures for earthquake resistance - Part 3: Assessment and retrofitting of buildings. Brussels: European Committee for Standardisation; 2005.

[38] Petersen MD, Harmsen SC, Jaiswal KS, Rukstales KS, Luco N, Haller KM, et al. Seismic hazard, risk, and design for south america. Bull Seismol Soc Am 2018;108:781-800. https://doi.org/10.1785/0120170002.

[39] Luco N, Ellingwood BR, Hamburger RO, Hooper JD, Kimball JK, Kircher CA. Risk-targeted versus current seismic design maps for the conterminous United States. SEAOC 2007 Conv. Proc., Squaw Creek, California, USA: 2007, p. 1-13.

[40] American Nuclear Society, Committee S, ANS-2.26 WG. ANSI/ANS-2.26-2004 2004;2004.

[41] CEN. Eurocode 0 - Basis of structural design 2002;1.

[42] Lazar Sinković N, Dolšek M. Fatality risk and its application to the seismic performance assessment of a building. Eng Struct 2020;205. https://doi.org/10.1016/j.engstruct.2019.110108.

[43] Tsang HH, Daniell JE, Wenzel F, Werner AC. A semi-probabilistic procedure for developing societal risk function. Nat Hazards 2018;92:943-69. https://doi.org/10.1007/s11069-018-3233- 
This paper was published in Engineering Structures. Please cite it as:

Caprinozzi S, Dolšek M. Seismic performance assessment of non-code-conforming and code-conforming supporting structures of elevated tanks using conventional and risk-based decision models. Engineering structures, 2021, 227, 111469, https://doi.org/10.1016/j.engstruct.2020.111469,

DOI: 10.1016/j.engstruct.2020.111469.

$\mathrm{Z}$.

[44] Tsang HH, Wenzel F. Setting structural safety requirement for controlling earthquake mortality risk. Saf Sci 2016;86:174-83. https://doi.org/10.1016/j.ssci.2016.02.028.

[45] Crowley H, Silva V, Martins L. Seismic Design Code Calibration Based on Individual and Societal Risk. 16th Eur. Conf. Earthq. Eng., Thessaloniki, Greece: 2018, p. 173-222.

[46] Crowley H, Polidoro B, Pinho R, Van Elk J. Framework for developing fragility and consequence models for local personal risk. Earthq Spectra 2017;33:1325-45. https://doi.org/10.1193/083116EQS140M.

[47] Iervolino I, Galasso C, Cosenza E. REXEL: computer aided record selection for code-based seismic structural analysis. Bull Earthq Eng 2010;8:339-62. https://doi.org/10.1007/s10518009-9146-1.

[48] Iervolino I, Maddaloni G, Cosenza E. A note on selection of time-histories for seismic analysis of bridges in Eurocode 8. J Earthq Eng 2009;13:1125-52. https://doi.org/10.1080/13632460902792428.

[49] Baker JW. Conditional Mean Spectrum: Tool for Ground-Motion Selection. J Struct Eng 2010;137:322-31. https://doi.org/10.1061/(ASCE)ST.1943-541X.0000215.

[50] Jayaram N, Lin T, Baker JW. A computationally efficient ground-motion selection algorithm for matching a target response spectrum mean and variance. Earthq Spectra 2011;27:797-815. https://doi.org/http://dx.doi.org/10.1193/1.3608002.

[51] Chiou B, Darragh R, Gregor N, Silva W. NGA project strong-motion database. Earthq Spectra 2008;24:23-44. https://doi.org/10.1193/1.2894831.

[52] Akkar S, Sandikkaya M a., Şenyurt M, Azari Sisi A, Ay BO, Traversa P, et al. Reference database for seismic ground-motion in Europe (RESORCE). Bull Earthq Eng 2014;12:311-39. https://doi.org/10.1007/s10518-013-9506-8.

[53] Baker JW. Efficient Analytical Fragility Function Fitting Using Dynamic Structural Analysis. Earthq Spectra 2015;31:579-99. https://doi.org/10.1193/021113EQS025M.

[54] Dolšek M, Brozovič M. Seismic response analysis using characteristic ground motion records for risk-based decision-making (3R method). Earthq Eng Struct Dyn 2016;45:401-20. https://doi.org/10.1002/eqe.2664.

[55] Jankovic S, Stojadinovic B. Probabilistic Performance-Based Seismic Demand Model For R/C Frame Buildings. 13th World Conf Earthq Eng 2004. 